\title{
The Fabrication and Characterization of bioengineered Ultra-High Molecular Weight Polyethylene-Collagen-HAp hybrid bone-cartilage patch
}

Yuliya Kan a, Julijana Cvjetinovic $^{\text {b,c }}{ }^{\text {, Eugene S. Statnik }}{ }^{\text {b,d }}$, Sergey V. Ryazantsev a , Natalia Yu. Anisimova $^{\text {b,e }}{ }^{\text {, Mikhail V. Kiselevskiy }}{ }^{\text {b,e }}$, Alexey I. Salimon ${ }^{a, b^{*}}$, Alexey V. Maksimkin ${ }^{b}$ and Alexander M. Korsunsky f,a

${ }^{a}$ Center for Energy Science and Technology, Skolkovo Institute of Science and Technology, Moscow, 121205, Russia.

${ }^{\mathrm{b}}$ Center of Composite Materials, National University of Science and Technology 'MISiS', Moscow, 119049, Russia.

${ }^{\mathrm{c}}$ Center for Photonics and Quantum Materials, Skolkovo Institute of Science and Technology, Moscow, 121205, Russia.

d Center for Design, Manufacturing, and Materials, Skolkovo Institute of Science and Technology, Moscow, 121205, Russia.

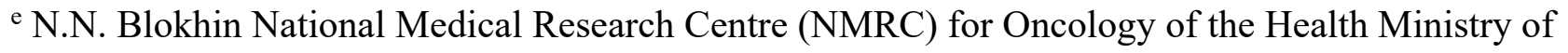
Russia, Moscow, 115478, Russia.

${ }_{\mathrm{f}}^{\mathrm{f}}$ Department of Engineering Science, University of Oxford, Oxford OX1 3PJ, United Kingdom.

* Email address for correspondence: A.Salimon@skoltech.ru

\section{Graphical Abstract}

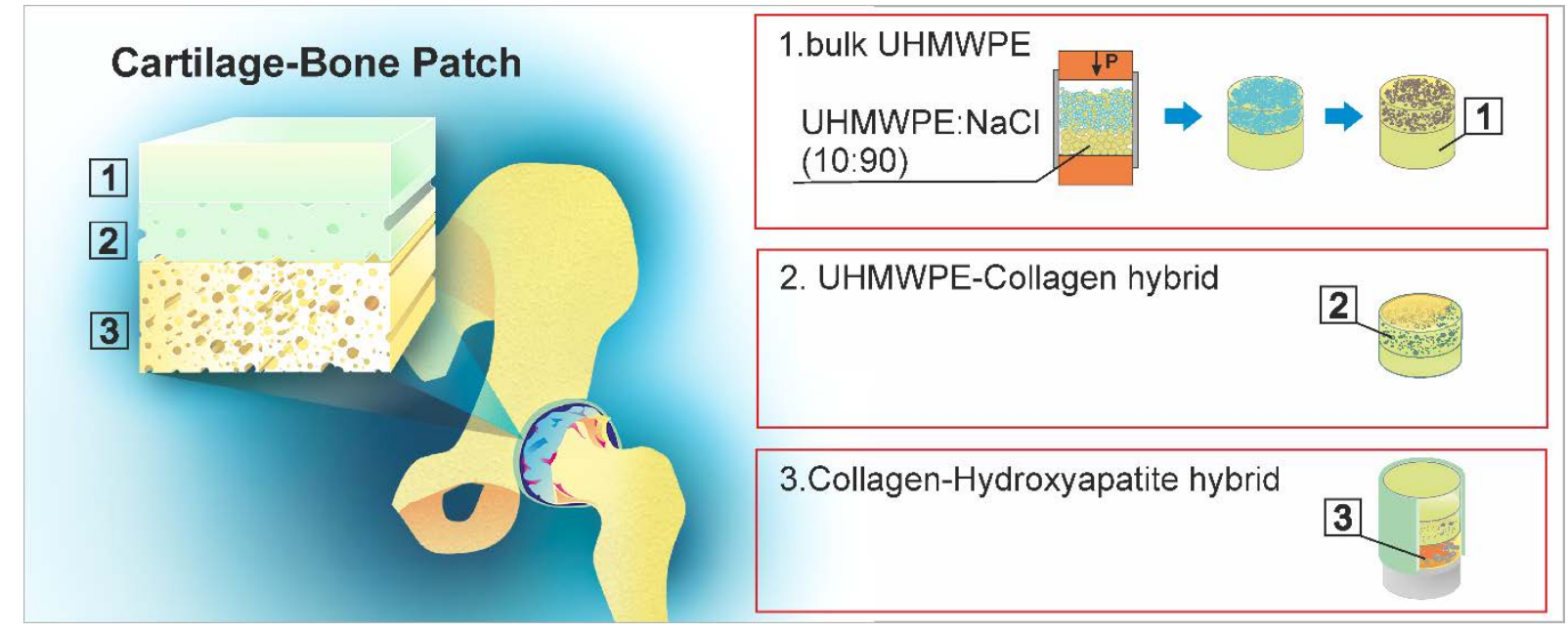

\section{Highlights}

- Bioinert ultra-high molecular weight polyethylene (UHMWPE) hybrid with bioactive components enhances bone tissue regeneration

- Glue-free junction of bulk and porous UHMWPE allows morphology variation whilst maintaining strong adhesion

- Attenuated Total Reflectance Fourier transform infrared (ATR FTIR) spectroscopy of collagen helps optimize the fabrication 


\begin{abstract}
:
A layered hybrid implant was designed and fabricated for the surgical replacement of worn cartilage to meet the complex requirements of biocompatibility and mechanics. The natural hierarchical structure was purposefully mimicked to improve the implant performance and integration. The hybrid was fabricated using three components: processed collagen gel, hydroxyapatite (HAp) powder and ultra-high molecular weight polyethylene (UHMWPE) in bulk and sponge form. The fabrication included hot molding, sacrificial templating, infusion, and freeze-casting stages. The hybrid had a porous transition layer made of porous UHMWPE impregnated with collagen by means of infusion. SEM and FTIR analyses confirmed successful collagen impregnation of porous UHMWPE. The morphology of transition layer was selected and produced to provide the UHMWPE pore size distribution in a range $\sim 50-150 \mu \mathrm{m}$ that is favorable for the osseointegration by osteoblast proliferation. Biocompatibility tests were carried out in vitro. The index of red blood cells hemolysis of $0.6 \%$ after 4 hours of co-incubation proves excellent biocompatibility of the fabricated UHMWPECollagen-HAp hybrid.
\end{abstract}

Keywords: Collagen, hydroxyapatite, freeze-casting, micromechanical bending test, electron microscopy, UHMWPE.

\title{
1. Introduction
}

Demanding reconstructive surgery applications call for continuous improvement of implant materials. Solutions based on metallic alloys, ceramics, polymers and their hybrids are being considered and optimized for safe bone and cartilage replacement. New biocompatible materials must meet a wide range of requirements in terms of different properties. In particular, suitable mechanical performance is required in terms of the static and dynamic stiffness and strength, fatigue durability and contact behaviour. In terms of biomedical performance, bioinertness and/or controlled biodegradability are sought [1]. Some of the studies focus on the synergy of components in order to develop new organic/inorganic hybrid materials, for instance, through nanosilicates being incorporated in polymer scaffolds [2].

Hip and knee joint replacement demands ensuring low friction and wear resistance, along with the properties listed above [3]. A complete joint replacement with stiff metal assembly and low friction polymer inserts is a widely commercialized engineering solution that delivers acceptable performance and durability [4], since failed implants require repair or replacements with traumatic surgical intervention to perform secondary operations that are particularly complicated for aged patients [5].

An artificial cartilage patch with bone integration offers an attractive alternative to reduce the instances of invasive surgical procedures. A multi-layered patch can be used locally to restore patches 
of damaged cartilage. The architecture of a hybrid involves the main load-bearing and low friction layer — bulk ultra-high molecular weight polyethylene (UHMWPE) — and two layers facilitating osseointegration and introducing a gradual change of mechanical properties.

UHMWPE is a popular prosthetic material for artificial hip joints [6] possessing low dry friction coefficient down to 0.05 [7] with excellent wear resistance [8]. Its tribological properties can be enhanced via the addition of carbon nanotubes [9], molecular chain orientation or radiation crosslinking [10]. It is highly bioinert, i.e. hardly interacts with the host tissues enhancing the stability of implant. Since bulk UHMWPE does not integrate with the host bone, it requires the creation of a porous structure to promote mechanical linking and "keying in" to establish a secure joint.

A bi-layered UHMWPE hybrid was fabricated in a one-stage hot molding process. The hybrid contains a low friction bulk layer and a porous layer that must have particular shape and size of open pores and the thickness of pore struts for optimal osseointegration [11], [12]. The use of a watersoluble sacrificial filler allows creating a gradient structure [13]. The impregnation of bi-layered UHMWPE with antibiotics and growth protein factors [14] as well as the introduction of marrowderived stem cells (MSC) can be used to facilitate faster osseointegration and new osteogenesis [15].

In the present study we pursue further development of the paradigm of multi-layered biomedical hybrids for faster osseointegration. Namely, porous UHMWPE impregnated with collagen gels and slurries can produce even better performance in reconstructive surgery. Collagen impregnation is based on the known phenomenon of stable adhesion of collagen layer to UHMWPE hybrid [16].

Collagen-based scaffolds have been investigated previously for artificial bone and cartilage [17], as well as for heart valve prostheses [18]. Collagen is a crucial fibrous component of mammalian tissues: bones, cartilage, tendons, and skin. It consists of a complex hierarchical system of protein fibers. Freeze-dried type I collagen has been reported in the literature as an extracellular matrix that promotes cell propagation and proliferation [19]. There is an extensive range of studies devoted to collagen as a base for fabricating bone replacement scaffolds [20], [21], [22], in combination with electrospun fibers and additives [23]. Scaffolds can be freeze-cast to create aligned open porosity, with crosslinking to improve the mechanical performance for osseointegration [18]. These core ideas underlie the concept of the multilayered patch presented herein.

Hydroxyapatite (HAp) is widely used as the main mineral component of bioactive materials as an accelerating additive for bone regeneration [24]. HAp is a natural created candidate for bone prostheses as it forms the mineral part of the mammalian bone. HAp powder has been successfully used in additive manufacturing to treat local injuries. 3D printing of HAp with burn-off binder for bone implants allows obtaining the required geometry [25], [26]. However, bulk HAp possesses rather limited strength and toughness in the absence of tight integration with an organic fibrous 
scaffold such as collagen. We therefore concluded that the use of a Collagen-HAp composite offers a promising avenue for further exploration: the fibrous collagen scaffold reduces the brittleness of pure HAp grafts, and also protects from fast HAp resorption [27]. Freeze-casting has been proposed as a method of creating versatile HAp-Polyvinyl Alcohol (PVA) systems with complex organization for load-bearing biomaterials [28]. Subsequent osseointegration involves the re-deposition of biogenic HAp, resulting in the formation of stable bone tissue.

Table 1. Recent studies of cartilage-bone implants

\begin{tabular}{|c|c|c|c|c|c|}
\hline Material & Features & Tensile modulus & $\begin{array}{l}\text { Fabrication } \\
\text { method }\end{array}$ & Application & References \\
\hline $\begin{array}{c}\text { UHMWPE- } \\
\text { collagen scaffold }\end{array}$ & $\begin{array}{c}\text { stable chemically } \\
\text { bonded collagen layer }\end{array}$ & - & $\begin{array}{l}\text { Acetic acid } \\
\text { treatment to tune } \\
\text { wettability of } \\
\text { UHMWPE; } \\
\text { Collagen soaking; } \\
\text { Plasma treatment } \\
\text { for UHMWPE } \\
\text { surface activation }\end{array}$ & $\begin{array}{c}\text { Tissue } \\
\text { engineering }\end{array}$ & [16] \\
\hline $\begin{array}{c}\text { UHMWPE/ } \\
\text { FMWCNT films }\end{array}$ & $\begin{array}{l}\text { reduce of wear rate; } \\
\text { multiple increase of } \\
\text { mechanical } \\
\text { characteristics }\end{array}$ & $\begin{array}{c}31-35 \mathrm{GPa} \\
\text { (UHMWPE/FMWCNT); } \\
0.72 \mathrm{GPa} \text { (bulk } \\
\text { UHMWPE) }\end{array}$ & $\begin{array}{l}\text { Extrusion } \\
\text { technique }\end{array}$ & Cartilage & [9] \\
\hline $\begin{array}{l}\text { Porous UHMWPE } \\
\text { scaffold }\end{array}$ & $\begin{array}{l}\text { controlled porosity } \\
(79 \%) \text { with mean } \\
\text { diameter of pore } 350 \\
\text { nm; } \\
\text { biocompatibility; }\end{array}$ & $\begin{array}{c}156 \mathrm{MPa} \text { (porous } \\
\text { UHMWPE) } \\
0.7 \pm 0.05 \mathrm{GPa} \text { (Bulk and } \\
\text { porous UHMWPE hybrid) } \\
\text { * required reinforcement } \\
\text { to reach cortical bone } \\
\text { strength }\end{array}$ & Hot molding & $\begin{array}{l}\text { Bone tissue } \\
\text { engineering }\end{array}$ & {$[11][12]$} \\
\hline Collagen sponge & $\begin{array}{l}\text { interconnected open } \\
\text { porous structure }\end{array}$ & $\begin{array}{l}400-700 \mathrm{kPa} \text { depending } \\
\text { on thickness }\end{array}$ & Freeze-drying & $\begin{array}{c}\text { Cell } \\
\text { cultivation }\end{array}$ & [19] \\
\hline $\begin{array}{l}\text { Collagen/oxidized } \\
\text { microcrystalline } \\
\text { cellulose scaffold }\end{array}$ & $\begin{array}{l}\text { hemostatic; } \\
\text { biodegradable }\end{array}$ & - & Freeze-drying & $\begin{array}{l}\text { Surgery } \\
\text { absorbing } \\
\text { material }\end{array}$ & [23] \\
\hline $\begin{array}{l}\text { Collagen/PLA } \\
\text { mesh }\end{array}$ & $\begin{array}{l}\text { high open porosity; } \\
\text { good cell proliferation; } \\
\text { fast recover after } \\
\text { mechanical load }\end{array}$ & $22.8 \pm 7.8 \mathrm{kPa}$ & $\begin{array}{l}\text { Melt spun PLA } \\
\text { fibers; } \\
\text { Freeze-drying of } \\
\text { mesh }\end{array}$ & $\begin{array}{l}\text { Cartilage } \\
\text { cellular } \\
\text { matrix }\end{array}$ & [17] \\
\hline \multirow[t]{2}{*}{$\begin{array}{l}\text { Collagen- } \\
\text { glycosaminoglycan } \\
\text { scaffold }\end{array}$} & $\begin{array}{l}\text { aligned high porous } \\
\text { structure }(99 \%) \text {; guided } \\
\text { thermal transition; }\end{array}$ & $590 \pm 0.04 \mathrm{kPa}$ & Freeze-drying & Heart Valve & {$[18]$} \\
\hline & $\begin{array}{l}\text { high porosity }(95 \%) \text {; } \\
\text { not aligned structure }\end{array}$ & $7.6 \mathrm{kPa}$ & Freeze-drying & $\begin{array}{c}\text { Tissue } \\
\text { engineering }\end{array}$ & [22] \\
\hline
\end{tabular}




\begin{tabular}{|c|c|c|c|c|c|}
\hline Collagen hydrogel & aligned structure & $567 \pm 134 \mathrm{kPa}$ & Freeze-drying & $\begin{array}{c}\text { Muscle, } \\
\text { tendon } \\
\text { engineering }\end{array}$ & {$[20]$} \\
\hline \multicolumn{7}{|c|}{$\begin{array}{l}\text { Hydroxyapatite } \\
\text { based ceramic }\end{array}$} & $\begin{array}{c}\text { cellular to lamellar } \\
\text { structure transition }\end{array}$ & - & $\begin{array}{c}\text { Freeze-casting } \\
\text { Sintering }\end{array}$ & Bone tissues & {$[28]$} \\
\hline
\end{tabular}

Table 1 shows that the material systems mentioned above were successfully used in fabricating cartilage and bone tissue scaffolds for reconstructive surgery.

In the present study, stepwise combination of hot molding, collagen impregnation and freezecasting/drying was used to produce multilayered hybrids. UHMWPE-Collagen-HAp hybrids were characterized with SEM, FTIR, and Raman spectroscopy for comprehensive evaluation. Characterization of the properties of each layer within the hybrid was carried out. Due to the complexity of the hybrid hierarchy and layer organization, once the layers were characterized in terms of the general morphology and collagen spatial distribution, similar assessments were performed for the layers after joining. The presence of collagen was confirmed using spectroscopic methods. The mechanical integration by collagen bridging established strong glue-free bonding between layers within the layered hybrid. Mechanical tests revealed the principal phenomena taking place in the hybrid under loading.

\section{Materials and Fabrication Methods}

\subsection{The Fabrication of UHMWPE-Collagen-HAp Hybrid}

\subsubsection{Bulk UHMWPE and Porous UHMWPE Preparation}

The UHMWPE powder GUR 4120 Ticona GmbH (Sulzbach, Germany) with a molecular weight of $5 \times 10^{6} \mathrm{~g} / \mathrm{mol}$ was used for the double-layered sample fabrication. The first layer originated from UHMWPE, while the porous layer was obtained using a mixture of UHMWPE and sodium chloride $(\mathrm{NaCl})$. The $\mathrm{NaCl}$ was used as the soluble filler with the following particle size distribution up to 0.8 $\mathrm{mm}-75 \%$; with $0.8 \mathrm{~mm}$ to $1.2 \mathrm{~mm}-25 \%$.

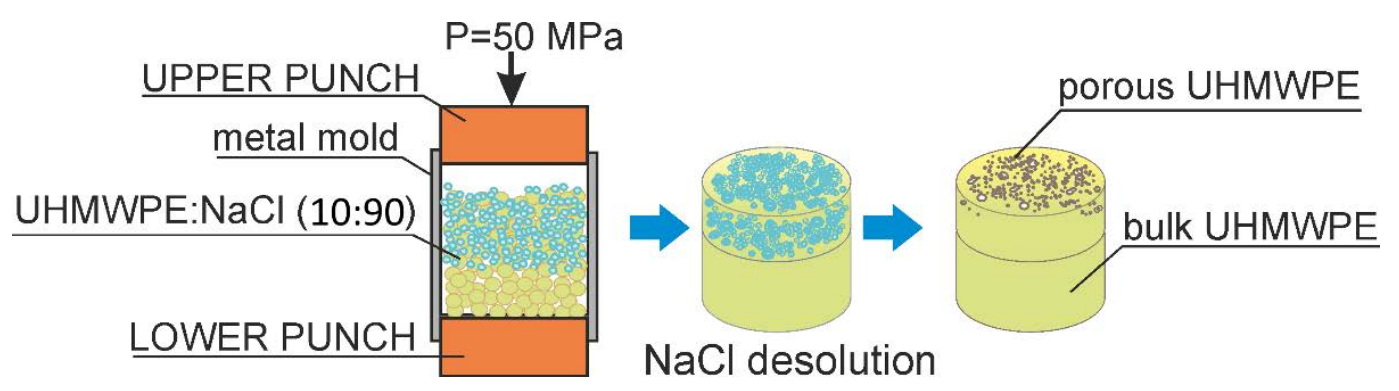


Fig. 1. The fabrication of multi-layered UHMWPE hybrids.

Fig. 1 contains the steps required to obtain the UHMWPE hybrid with varied porosity. Solid-state mixing of UHMWPE powder and $\mathrm{NaCl}$ was performed in a planetary ball mill Fritsch Pulverisette 5 Fritsch GmbH (Idar-Oberstein, Germany) with the rotation speed $90 \mathrm{rpm}$. The powders were loaded in $500 \mathrm{ml}$ agate bowls with corundum grinding balls of diameter $10 \mathrm{~mm}$ used as milling bodies. Mixing was carried out under low energy conditions to prevent the reduction of particle size. As a result, a mixture of UHMWPE and $\mathrm{NaCl}$ of specific composition was obtained, with the mass ratio 1:9 [11]. Hot molding under the pressure of $50 \mathrm{MPa}$ and a temperature of $180^{\circ} \mathrm{C}$ processed the layered UHMWPE hybrid for 2 hours. The samples were cylinders with a diameter of $26 \mathrm{~mm}$ and the height of a bulk layer of $7 \mathrm{~mm}$ and a thick porous layer of $3 \mathrm{~mm}$. The obtained specimens were rinsed with distilled water to release the fillers and dried at $70{ }^{\circ} \mathrm{C}$ for 1 hour.

\subsubsection{Porous UHMWPE Impregnated with Collagen}

The layered UHMWPE hybrid was impregnated with 2 wt. \% collagen gel solution BioProduct Ltd. (Moscow, Russia) using three different routes shown in Fig. 2. The first route of impregnation was spreading of collagen gel on the top surface (Fig. 2a). Fig. 2b illustrates the second route of impregnation via vacuum infiltration whereas the air evacuated from the pores was replaced with collagen intrusion into the pores.

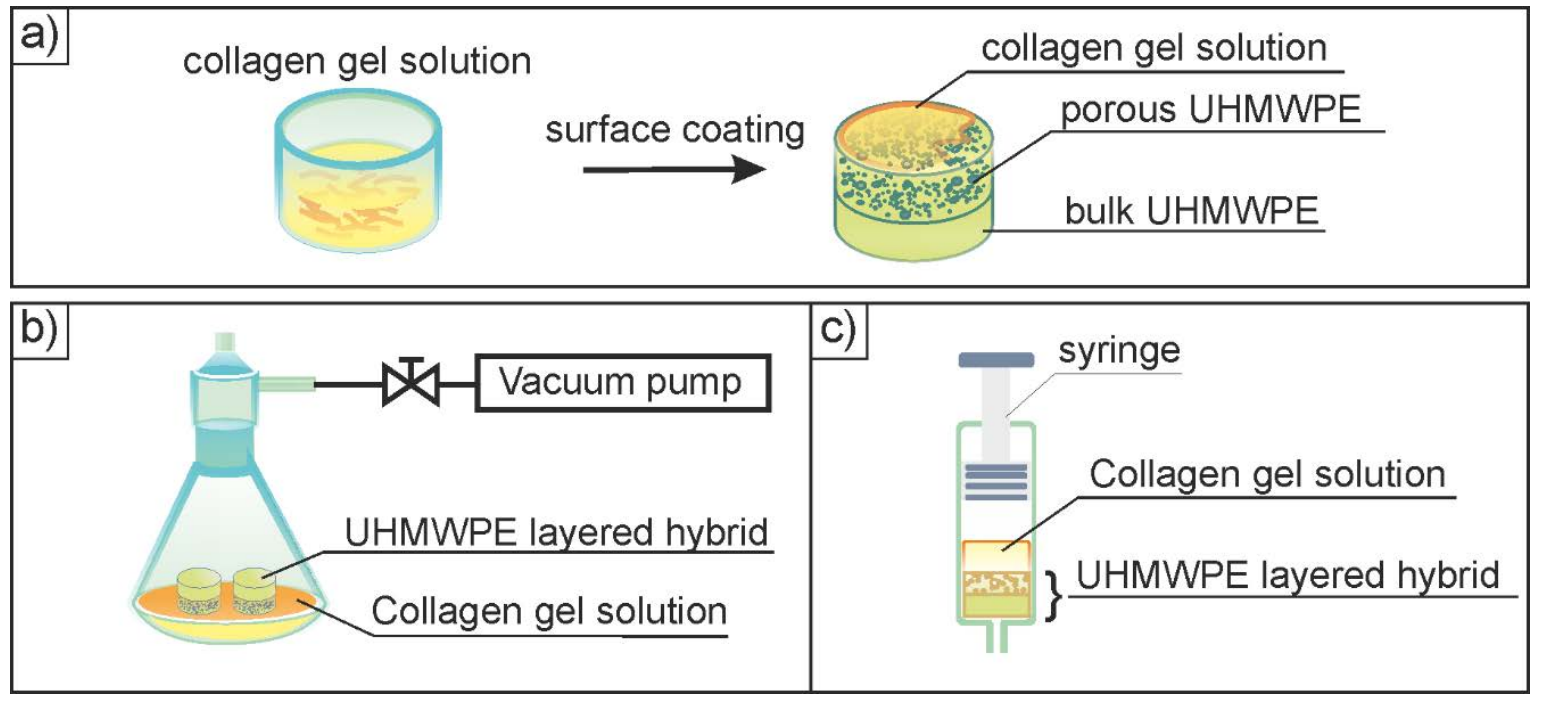

Fig. 2. Different methods of collagen impregnation.

The third route involved a syringe as a chamber to load the porous specimen with collagen by the assigned pressure (Fig. 2c). The impregnation of UHMWPE hybrid was a preliminary step before the freeze-drying process. 


\subsubsection{Collagen-HAp Hybrid}

The 2 wt. \% collagen gel solution in $0.02 \mathrm{M}$ acetic acid was mixed with HAp powder (NGO Polystom, Moscow, Russia) with the mass ratio 90:10 and 70:30, respectively. The slurry was stirred using alumina milling bodies $(\mathrm{d}=5 \mathrm{~mm})$ using SPEX ${ }^{\mathrm{TM}}$ SamplePrep8000M Mixer/Mill (Stanmore, UK) for $20 \mathrm{~min}$ at the $1425 \mathrm{rpm}$. A cylindrical mold was consisted of PLA 3D-printed walls and thermally conductive aluminum base to generate predominantly vertical heat flow for the guided formation of ice crystals. Freeze-casting included primarily cooling down of layered UHMWPE hybrid and collagenous slurry to provide glue-free junction (Fig.3). The frozen specimen was held in Free Zone benchtop device Labconco ${ }^{\circledR}$ (Kansas City, USA) at $-30{ }^{\circ} \mathrm{C}$ for 48 hours.

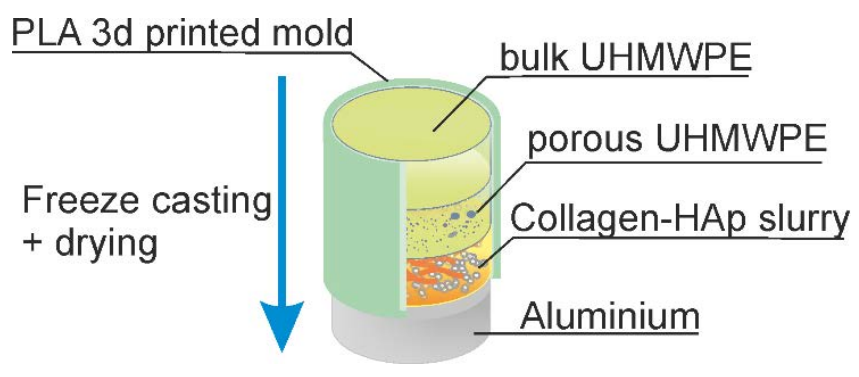

Fig. 3. The flow-chart process of freeze-casting.

\subsubsection{Sterilization}

UHMWPE-Collagen-HAp hybrids were subjected to radiation sterilization using linear electron accelerator UEL-10-15-C JSC NIIEFA (Saint Petersburg, Russia). The energy of the accelerated electrons in the nominal mode is $10 \mathrm{MeV}$, the output power is $12 \mathrm{~kW}$. Standard irradiation doses (up to $20 \mathrm{kGy)}$ were used.

\subsection{Characterization Methods}

\subsubsection{Scanning Electron Microscopy (SEM)}

The morphology of porous UHMWPE sample and multilayered UHMWPE-Collagen-HAp hybrid was examined using scanning electron microscopy (SEM) in VEGA3 microscope (Tescan, Brno, Czech Republic) with the accelerating voltage of $10 \mathrm{kV}$ and $20 \mathrm{kV}$ and analyzed using software VEGA TC. The sample preparation included platinum-coating by Auto Fine Coater JFC-1600 (JEOL, USA). The morphology of UHMWPE-Collagen hybrids was examined using Phenom ProX scanning electron microscope with the accelerating voltage of $10 \mathrm{kV}$. Elemental distribution of hybrid layers was performed using energy dispersive X-ray analysis. 


\subsubsection{Contact Angle Measurement}

The wettability of obtained UHMWPE hybrid was assessed to monitor the collagen affinity during the collagen impregnation. The contact angles were measured using EasyDrop Shape Analyzer KRÜSS (Hamburg, Germany) using a static sessile drop method at room temperature. For every measurement, $5 \mu \mathrm{L}$ of water and collagen gel solution was dropped on the sample surface by the dosing dispenser. The baseline and contact angle were determined via Drop Shape Analysis.

\subsubsection{Vibrational Spectroscopy}

The spectroscopy methods were aimed to trace collagen throughout the hybrid to evidence the successful integration of layers. Attenuated Total Reflectance Fourier transform infrared spectroscopy (ATR FTIR) was used to examine the chemical structure of collagen-derived biomaterials. ATR FTIR spectra of collagen-based hybrids were collected in the wavelength range of 4000-600 $\mathrm{cm}^{-1}$ using a stand-alone FTIR microscope LUMOS (Bruker) equipped with a germanium ATR crystal. Analogous spectra of collagen film (prepared by drying of the 2 wt. \% collagen gel solution in acetic acid in room temperature) and HAp powder were obtained as reference data. ATR FTIR spectra of the porous UHMWPE samples before and after surface modification and spectra of the hybrid UHMWPE-Collagen were recorded in the wavelength range of $4000-400 \mathrm{~cm}^{-1}$ using Nicolet 380 (Thermo Scientific, Massachusetts, USA) spectrometer equipped with diamond ATR crystal.

Raman spectra were obtained using DXRxi Raman imaging microscope Thermo Fisher Scientific (Massachusetts, USA) with the laser wavelength of $532 \mathrm{~nm}$. Decellularized extracellular matrix (DEM) and fibers of collagen type I from calf skin Sigma-Aldrich (St. Louis, Missouri, USA) were used as reference materials. DEM taken from an ethically mortified dog was provided by N.N. Blokhin MRCO Institute (Moscow, Russia) in accordance with the regulations in force [29].

\subsubsection{Micromechanical Bending Test}

The cracking and flaking behavior of freeze-dried collagen and Collagen-HAp forming part of UHMWPE-Collagen-HAp hybrid were investigated using the in-situ transverse three-point bending test method. In situ three-point bending test was performed using a Deben micro-tester (Deben, UK) with a $1 \mathrm{kN}$ tensile module under Altami 6C optical microscope (St. Petersburg, Russia), to study the microstructure of materials during the deformation process. Mechanical testing of a layered sample is schematically illustrated in Fig. 4. The motorized tensile module realized a crosshead displacement velocity of $1.0 \mathrm{~mm} / \mathrm{min}$. 


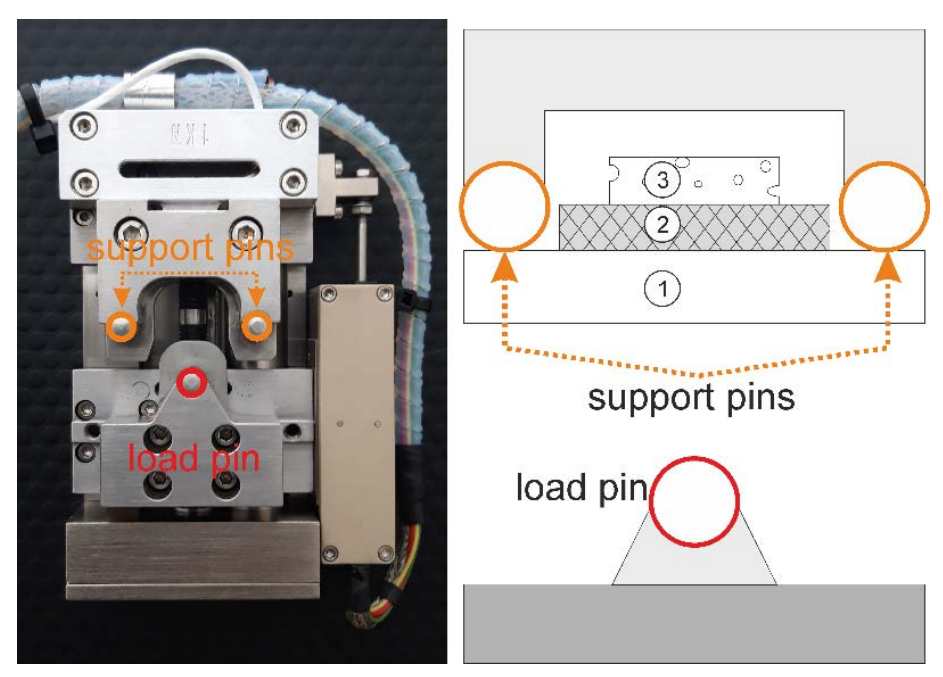

Fig. 4. Scheme of the 3-point bending experiment: 1. bulk UHMWPE; 2. porous UHMWPE impregnated with collagen; 3. Collagen-HAp hybrid.

\subsubsection{Biocompatibility Tests In Vitro}

According to the introduction part, the Collagen-HAp layer has positive track record in biomedical applications. Bulk UHMWPE is widely referred as bioinert, however, the middle UHMWPECollagen layer has not been tested in term of biocompatibility. Since the biocompatibility of UHMWPE-Collagen-HAp hybrid is mandatory requirement, the testing of UHMWPE sponge impregnated with collagen is to be carry on. Hence, two sterile UHMWPE-Collagen hybrids were washed by $0.9 \%$ sodium chloride solution (PanEco, Russia) before analysis. Then each sample was divided into 5 parts, with weight $0.020 \pm 0.003 \mathrm{~g}$.

For hemolysis studies, red blood cells (RBCs) were isolated from blood and suspended in phosphate-buffered saline (PBS) [30]. $500 \mu \mathrm{L}$ RBC suspension was introduced into wells of a 24well plate (Thermo Scientific NUNC, Rochester, USA) with the samples of the UHMWPE-Collagen hybrids. Positive and negative controls were produced by adding $100 \mu \mathrm{L}$ of Triton-X-100 SigmaAldrich (St. Louis, Missouri, USA) or PBS, respectively. The plate with RBCs and alloy samples was incubated at $37^{\circ} \mathrm{C}$ for 4 hours. Probes for analysis were collected at 1,2, and $4 \mathrm{~h}$ after the beginning of the test. The percentage of hemolysis was calculated as described in reference [30]. Optical density (OD) of the supernatant was measured at $540 \mathrm{~nm}$ using a Labsystems Multiscan MS plate reader. Tested samples were described as biocompatible if the value of hemolysis did not exceed $10 \%$ at 4 hours after the start of co-incubation of the cells with the samples [31].

For the evaluation of the cell vitality, $1 \mathrm{ml}$ of mouse white blood cells (WBCs) in RPMI-1640 medium supplemented with $10 \%$ fetal bovine serum (Thermo Scientific, USA), $100 \mu \mathrm{g} / \mathrm{ml}$ penicillin, 
$100 \mu \mathrm{g} / \mathrm{mL}$ streptomycin, and $2 \mathrm{~mL}$-glutamine (All Gibco, Carlsbad, USA) in the concentration $5.4 \cdot 10^{4}$ cells $/ \mathrm{ml}$ (94\% viability) were cultivated with tested samples in a 24 -well plate (Nunc, USA) at $37{ }^{\circ} \mathrm{C}$ in a humidified atmosphere with $5 \% \mathrm{CO}_{2}$. The control WBCs were treated with only RPMI 1640. After incubation for 24 h, $20 \mu \mathrm{L}$ 3-(4.5-dimethylthiazol-2-yl)-2.5-diphenyltetrazolium bromide (MTT) (Sigma) with a concentration of $5 \mathrm{mg} \cdot \mathrm{mL}^{-1}$ was added into each well. The plates were incubated for $4 \mathrm{~h}$ under cell culture conditions. Subsequently, $500 \mu \mathrm{L}$ dimethyl sulphoxide (PanEco, Moscow, Russia) was added to the cells by replacing the medium, to dissolve the formazan crystals. OD of the solution $(100 \mu \mathrm{L})$ was measured at $540 \mathrm{~nm}$ in 96-well plates. The vitality of WBCs was calculated as described in [31].

Biocompatibility was proved in case the value of hemolysis did not exceed $10 \%$ at 4 hours after the start of co-incubation of the cells with the samples and viability of sample-treated WBCs was not significantly changed or higher in comparison with the intact control $(p>0.05)$ [32]. Tests were performed with triplicate assays and repeated three times using separate samples. OD measurements were presented as mean \pm standard deviation (SD). A comparative analysis was performed using the Mann-Whitney $U$ test. The difference was considered significant at $p<0.05$. The described study was approved by the local ethics committee of N.N. Blokhin NMRC for oncology (Moscow, Russia).

\section{Results and Discussion}

\subsection{Sample Morphology}

The primary materials of UHMWPE-Collagen-HAp hybrid included the powders and the collagen gel solution. The provided powders were assessed using laser particle size analyzer Analysette 22 (Fritsch, Idar-Obserstein, Germany). The unimodal size distribution for UHMWPE powder indicated the predominant size of particles $5 \mu \mathrm{m}$ (Supporting Materials, Fig. S1.1). HAp powder showed a bimodal distribution, with the most abundant probability of particles in the range from 16.7 to 18.36 $\mu \mathrm{m}$, and the smaller fraction having grain size below $2 \mu \mathrm{m}$.

Pores of irregular sizes emerged after the removal of the sacrificial $\mathrm{NaCl}$ and resulted in a wide range distribution illustrated in Fig. 5a. Fig. 5b demonstrated the pore surface of the cellular UHMWPE. The inner surface of the pore was observed to offer a suitable scaffold for the cell growth and attachment [33]. 

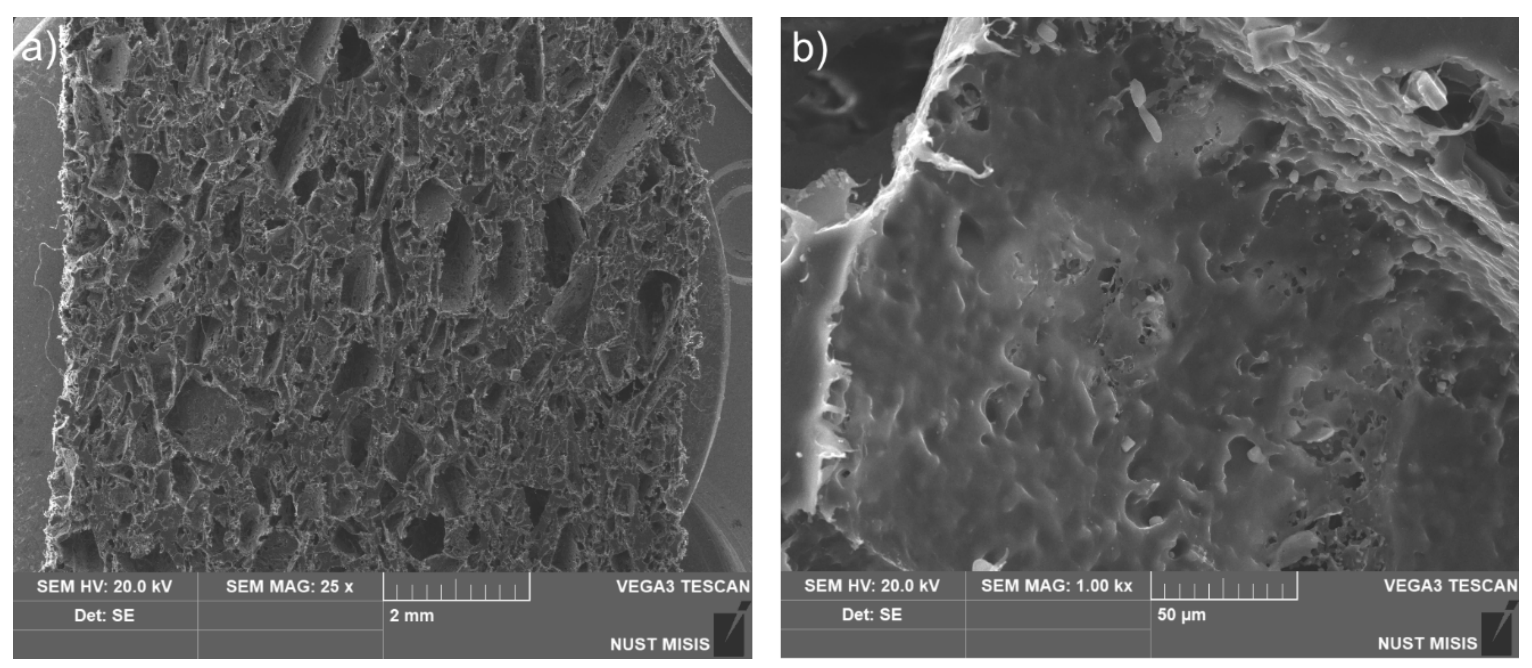

Fig. 5. SEM images of: a) porous UHMWPE; b) the inner surface of a UHMWPE pore.

Diverse collagenous structures were obtained as a result of room temperature drying and Freezedrying. Fig. S1.2 showed desiccated collagen films with the single fibre up to $2 \mu \mathrm{m}$ in length (see Supporting Materials). An assessment of porosity was performed to find the penetration limit of collagen within the UHMWPE porous structure. The pore size distribution was evaluated through processing the SEM images using Fiji package based on the open-source software ImageJ. At the first stage, each pore was classified and essentially separated by Gaussian blur filter (blurring radius 2.0 pixels) and segmented using Shanbhag threshold approach. The assumption of spherical pore shape was made, and circular cross-sections were tracked to output the number and areas of pores. The area data was converted into radius with further logarithm transformation. Fig. S1.3 (see Supporting Materials) demonstrates the mean pore size for collagen sponge of 20-54 $\mu \mathrm{m}$ while for porous UHMWPE these values span from 54-148 $\mu \mathrm{m}$, respectively.

Moreover, distributions were tested against the Gaussian hypothesis with Pearson's chi-squared criterion. Results showed low p-values, namely, $3 \times 10^{-2}$ for porous UHMWPE and $3 \times 10^{-13}$ for collagen that less than confidence coefficient equals to $5 \times 10^{-2}$. The hypothesis was rejected.

\section{Description of Collagen Impregnation Facilitated by Three Methods}

Fig. 6a showed the morphology of UHMWPE-Collagen hybrid obtained by the first method via the mechanical spreading of collagen over the surface of porous UHMWPE. 

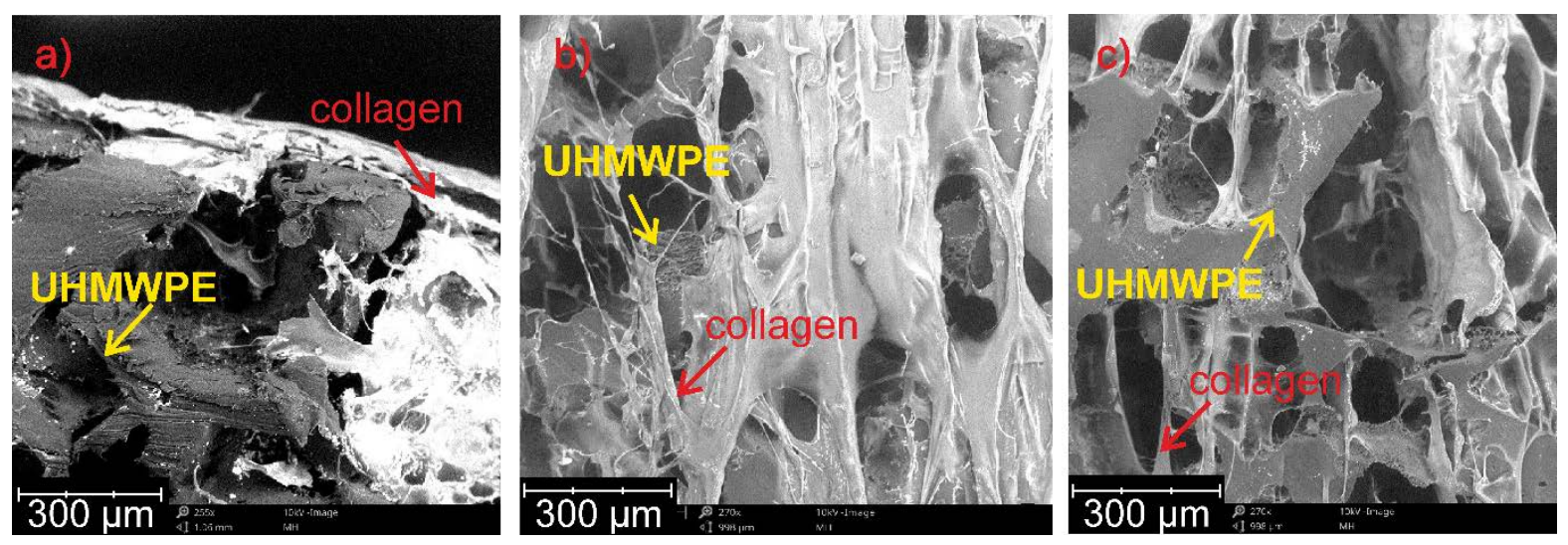

Fig. 6. SEM images of UHMWPE-Collagen hybrid prepared by: the mechanical spreading of collagen (a); vacuum infusion (b); syringe impregnation (c).

The results showed a massive collagen layer on the surface of UHMWPE with a negligible amount of collagen inside UHMWPE pores. Therefore, the first method of impregnation facilitated limited depth penetration of collagen into open-cell porous UHMWPE.

Fig. $6 \mathrm{~b}$ showed a large amount of applied collagen via vacuum infusion in the cellular UHMWPE. The last method involved the impregnation of collagen with the help of syringe manually. Fig. 6c reveals the reduced amount of collagen located in the pores of UHMWPE. Syringe infusion was much more applicable for UHMWPE-Collagen hybrid preparation.

\section{UHMWPE-Collagen-HAp Hybrid}

The SEM image of UHMWPE-Collagen-HAp hybrid performed the morphology of layer stacking in Fig. 7. The interface between bulk UHMWPE and UHMWPE-Collagen layers was demonstrated in Fig. 8a.

a)

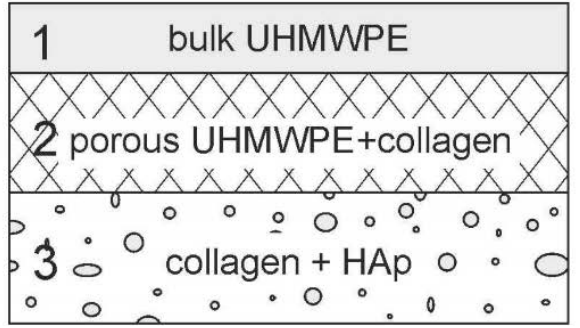

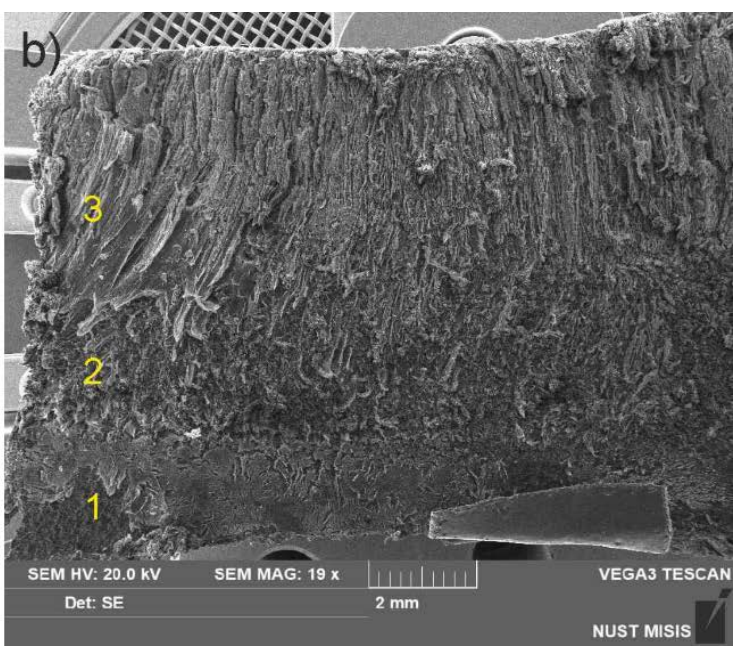

Fig. 7. The architecture of the multilayered UHMWPE-Collagen-HAp hybrid: schematic diagram (a); SEM image of the produced 'sandwich' (b). 
The roughness of metal mold (piston) determined the surface roughness of bulk UHMWPE $\left(\mathrm{R}_{\mathrm{z}}=\right.$ $0.2 \mu \mathrm{m})$. Bulk UHMWPE was covered with collagen after impregnation and Freeze-drying. The border was visible due to the different porosity of UHMWPE layers. Bulk-to-porous transition layer showed no delamination or other flaws promising both strong binding between layers and smooth mechanical performance gradient.

Fig. $8 \mathrm{~b}$ gave a representation of the interaction of porous UHMWPE-Collagen layer and 90Collagen10HAp hybrid. Collagen-HAp layer was differentiated by the aligned nature of the open porous structure.
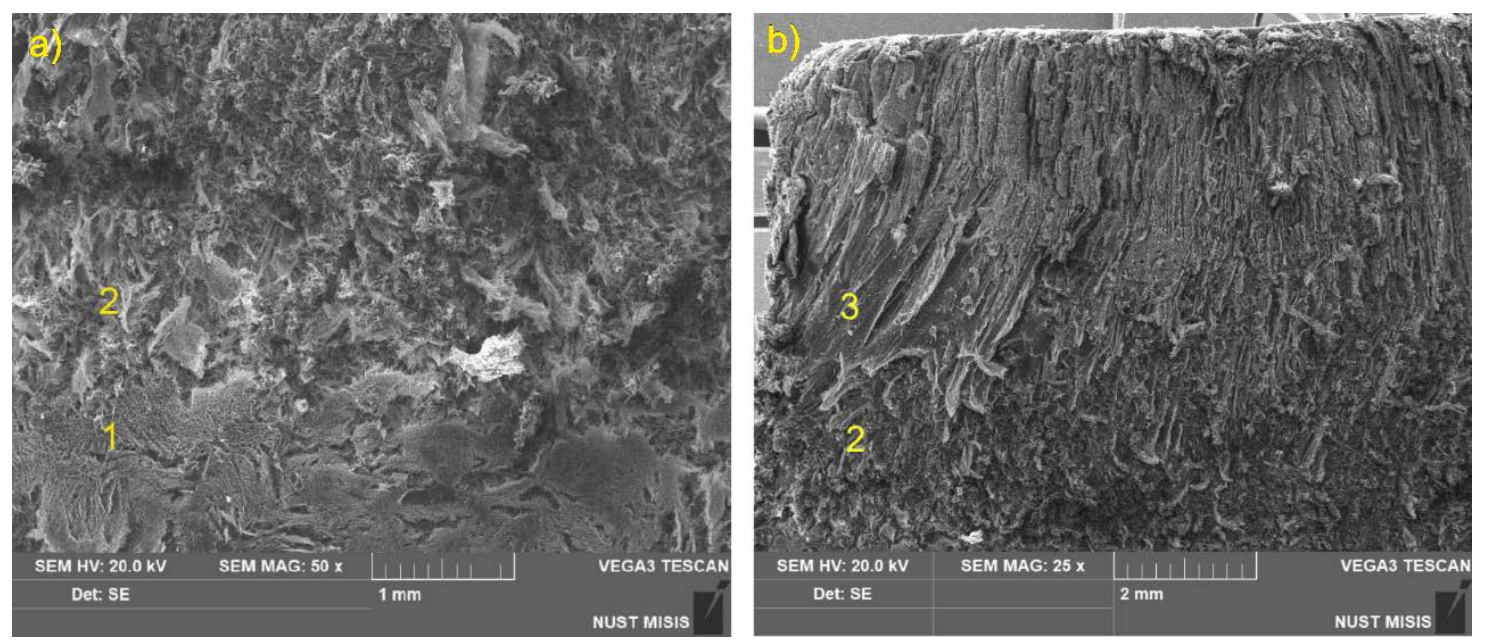

Fig. 8. SEM images of the transition layer between: bulk UHMWPE and UHMWPE-Collagen (a); UHMWPE-Collagen and 90Collagen10HAp hybrid (b).

EDX analysis provided the element distribution found in the porous UHMWPE-Collagen layer (Fig. S2.1). The presence of phosphate group was due to the method of hybrid preparation, whereas Collagen-HAp slurry penetrated throughout the layers during freeze-drying and casting. The elemental maps of Ca, P and S indicated the homogeneous distribution of hydroxyapatite (Fig. S2.2).

\subsection{Contact Angle Measurement}

UHMWPE is a hydrophobic polymer, in contrast with hydrophilic collagen. It seems to be the main reason for the limited penetration of collagen into porous UHMWPE at the impregnation stage. 


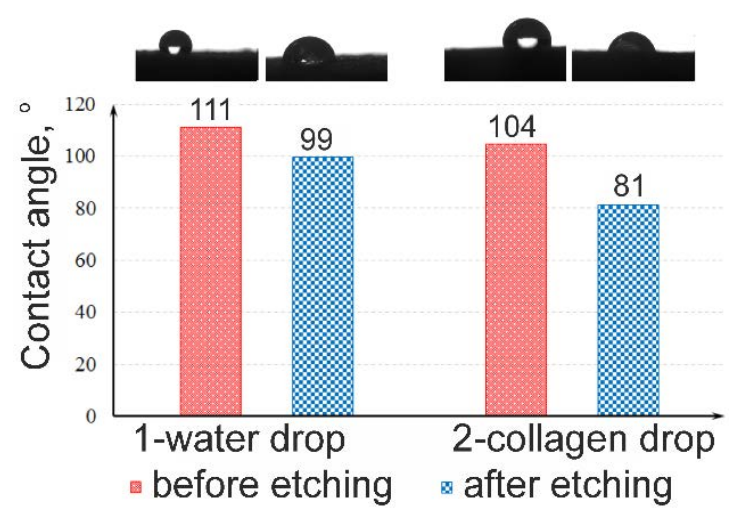

Fig. 9. Contact angle measurement of the UHMWPE sample before/after modification.

The porous UHMWPE was established hydrophobic almost like bulk UHMWPE since the contact angles were higher than $90^{\circ}$. The contact angle of as-received UHMWPE sample after dropping water on the surface was $111^{\circ}$ and diminished to $99^{\circ}$ after specific modification - etching by a reagent based on the chromic acid solution. Conversely, the contact angle of UHMWPE-Collagen surface was $104^{\circ}$ then decreased down to $81^{\circ}$ after etching, as shown in Fig. 9.

According to the results, the wettability of UHMWPE in hybrids was improved after chemical modification. The change of contact angles can be explained by the formation of hydrophilic groups, such as hydroxyl $(-\mathrm{OH})$ and carbonyl groups $(-\mathrm{C}-\mathrm{O},-\mathrm{C}=\mathrm{O})$, which were identified by FTIR spectroscopy of modified samples (see below). As expected, modest wettability of UHMWPE can be noticeably improved due to aggressive etching. However, the method could deteriorate biocompatibility characteristics and since should be avoided. Therefore, the control methods over the collagen impregnation were implemented. The molecular spectroscopy methods such as FTIR and Raman were applied in order to detect collagen in the depth of polymer poroid.

\subsection{FTIR Spectroscopy}

Fig. 10a illustrated ATR FTIR spectra of the 70Collagen30HAp hybrid (30 wt. \% of HAp) and dried collagen film and HAp (powder). The infrared spectrum of collagen exhibited a series of characteristic bands [34], namely Amide I (1638-1646 cm-1), Amide II (1541-1157 cm $\left.\mathrm{cm}^{-1}\right)$, Amide III (1350-1200 $\left.\mathrm{cm}^{-1}\right)$, as well as Amide A $\left(3312 \mathrm{~cm}^{-1}\right)$ and Amide B (2932 and $\left.3060 \mathrm{~cm}^{-1}\right)$. Amide A absorption band corresponded to NH stretching vibration, while asymmetrical stretching vibrations of $\mathrm{CH}_{2}$ group were represented by the Amide $\mathrm{B}$ band. Amide I band was associated with $\mathrm{CO}$ stretching vibration in polypeptide backbone. Amide II and Amide III bands were generally associated with both $\mathrm{NH}$ in-plane bending and $\mathrm{CN}$ stretching vibrations [35]. Amide III band was highly sensitive to the secondary structure folding [36]. Comparing the spectra of the 
70Collagen30HAp hybrid and neat collagen film revealed that the similarity except for differences in the Amide III band in Fig. 10b. Amide A absorption band corresponded to NH stretching vibration, while the asymmetric stretching vibration of $\mathrm{CH}_{2}$ group was represented by the Amide $\mathrm{B}$ band (see Fig. 10c).
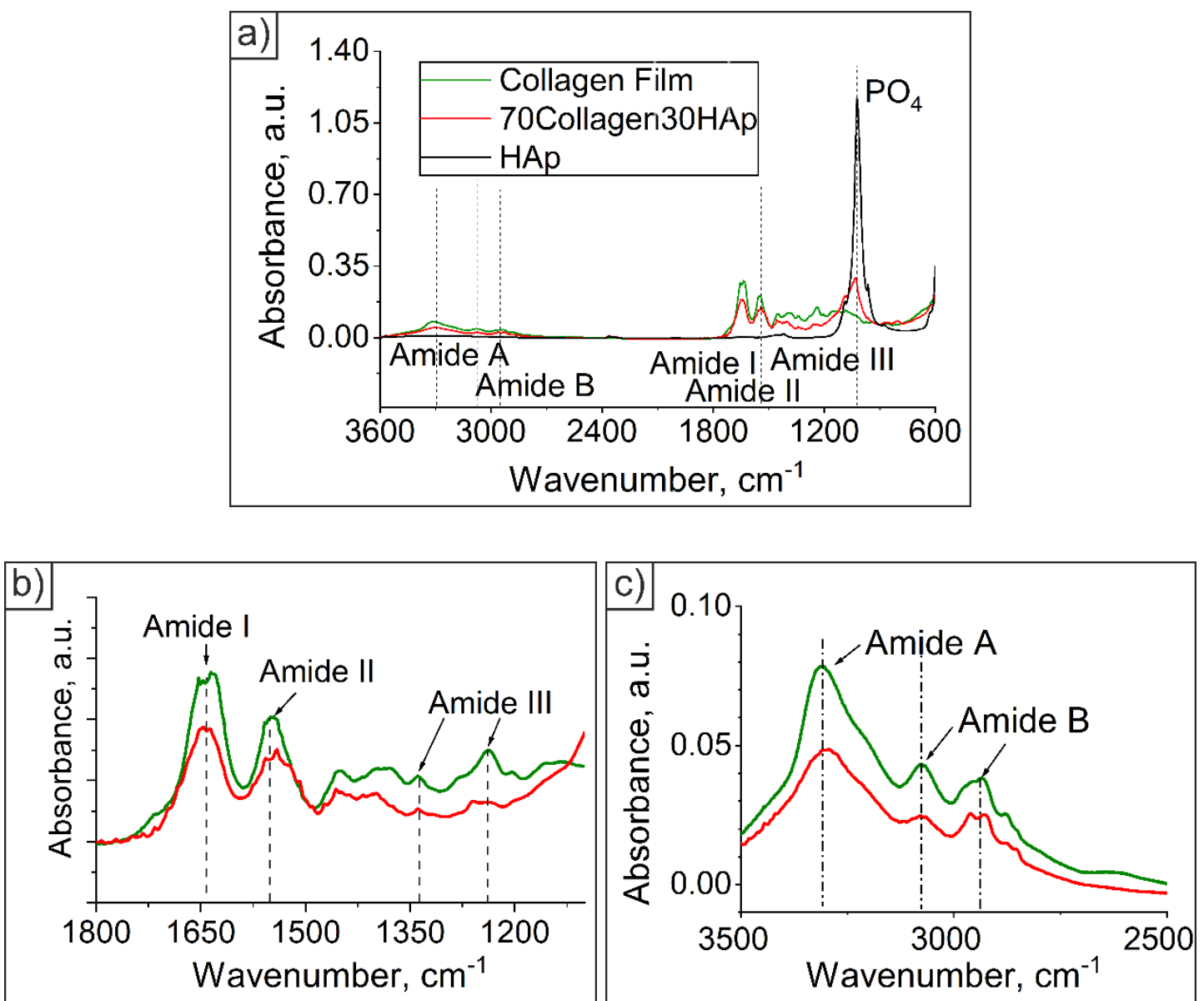

Fig. 10. ATR FTIR spectrum of the Collagen-HAp hybrid as compared to those for pure collagen and HAp: a) whole spectrum (3600-600 $\mathrm{cm}^{-1}$ range), b) Amide I-Amide III bands in the 1800-1100 $\mathrm{cm}^{-1}$ range, c) Amide A and Amide B bands (3500-2500 $\left.\mathrm{cm}^{-1}\right)$.

The strong band centered at $1029 \mathrm{~cm}^{-1}$ was accompanied with a weak satellite at $1088 \mathrm{~cm}^{-1}$, as well as the absorption feature near $600 \mathrm{~cm}^{-1}$ observed in the spectrum of the 70Collagen $30 \mathrm{HAp}$ hybrid correspond to the phosphate group vibrations of HAp that was verified by comparison with the reference spectrum of pure HAp powder. These signals evidence the HAp presence after the freezecasting of samples [36]. 


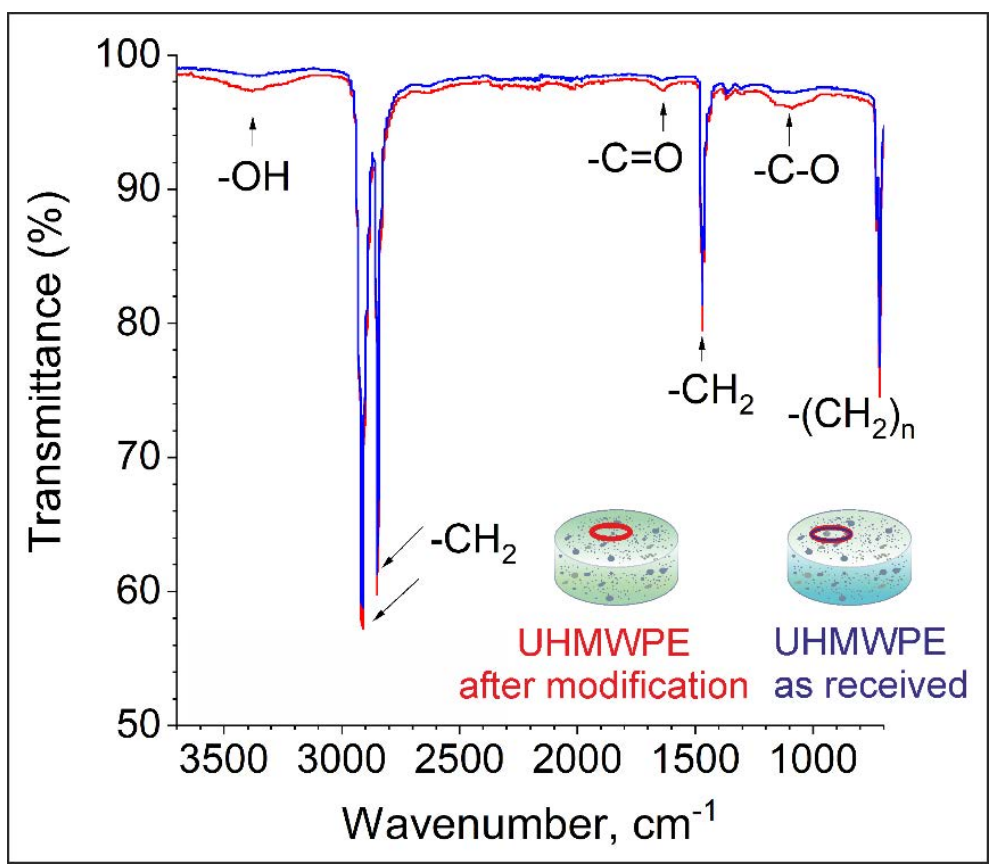

Fig. 11. ATR FTIR spectra of UHMWPE samples before/after etching $\left(3700-700 \mathrm{~cm}^{-1}\right)$.

UHMWPE samples after wettability modification were characterized by FTIR spectroscopy. Fig.11 illustrated the FTIR spectra of as received and chromic acid-modified UHMWPE. The absorption peaks of $2914,2847,1471$, and $717 \mathrm{~cm}^{-1}$ were attributed to methylene $-\mathrm{CH}_{2}$ asymmetrical stretch vibration, $-\mathrm{CH}_{2}$ symmetrical stretch vibration, $-\mathrm{CH}_{2}$ non-symmetry changing angle vibration, and $\left(\mathrm{CH}_{2}\right)_{\mathrm{n}}$ swing in-plane vibration, respectively [37], [38]. The broadband around $3400 \mathrm{~cm}^{-1}$ observed the presence of the hydroxyl group $-\mathrm{OH}$ in the spectra of UHMWPE hybrid. The vibrations bands around $1633 \mathrm{~cm}^{-1}$ and $1120 \mathrm{~cm}^{-1}$ referred to oxygen-based carbonyl groups $-\mathrm{C}=\mathrm{O}$ and $-\mathrm{C}-\mathrm{O}$, respectively [38]. Thus, the surface etching with chromic solution caused an increase of the oxygencontaining group.

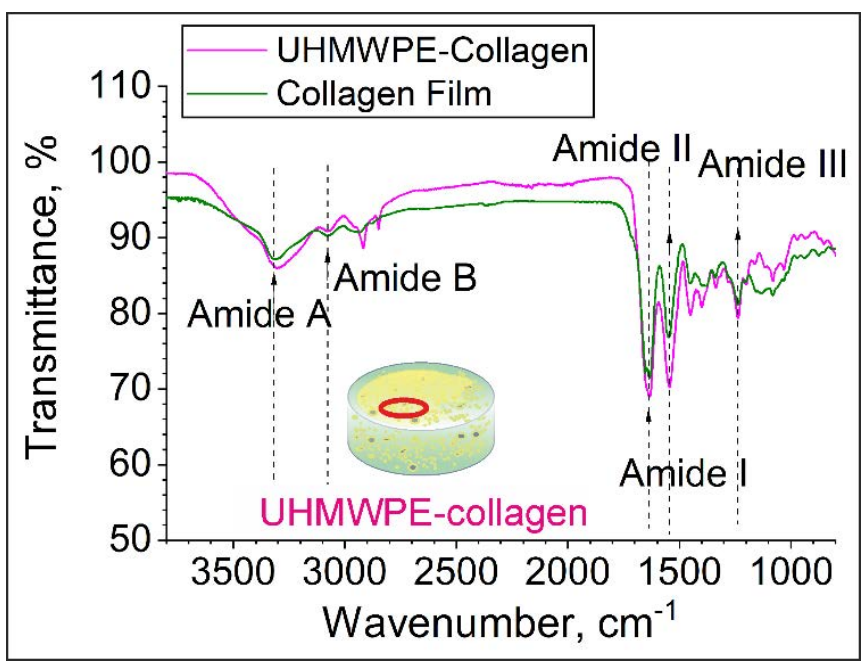

Fig. 12. FTIR spectra of UHMWPE-Collagen surface. 
FTIR spectrum of hybrid UHMWPE-Collagen surface was presented in Fig. 12. The spectrum contained Amide A, Amide B bands at $3304 \mathrm{~cm}^{-1}$ and $3068 \mathrm{~cm}^{-1}$ and Amide I, Amide II, Amide III bands at $1653 \mathrm{~cm}^{-1}, 1544 \mathrm{~cm}^{-1}$ and $1237 \mathrm{~cm}^{-1}$, respectively. The absorption features corresponded to specific Amide groups for collagen. Hence, FTIR spectroscopy proved the presence of collagen on UHMWPE surface.

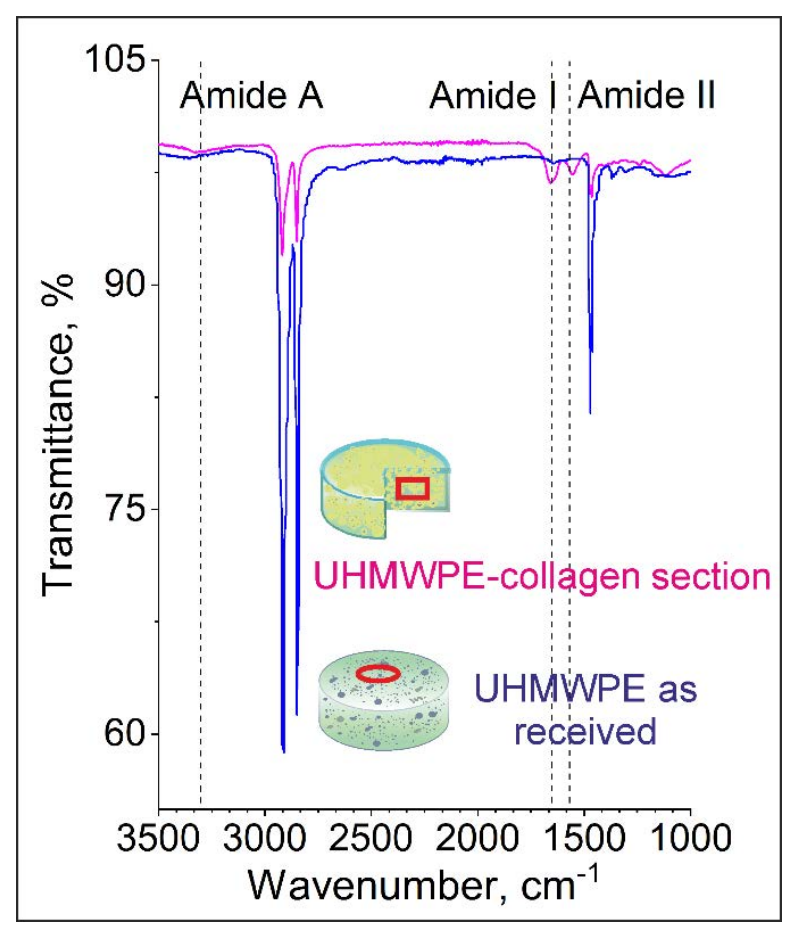

Fig. 13. ATR FTIR spectra of UHMWPE-Collagen cross-section (violet solid trace) as compared to the UHMWPE (blue solid trace).

FTIR spectrum of a section of UHMWPE-Collagen composite was shown in Fig. 13. Besides, the prominent absorption bands of polyethylene (doublet $2914 / 2847 \mathrm{~cm}^{-1}$ and peak at $1471 \mathrm{~cm}^{-1}$ ), there were two additional signals, which were Amide I and Amide II bands - two most intensive infrared absorption features of collagen (see Fig. 12).

\subsection{Raman Spectroscopy}

Raman spectrum of 90Collagen10HAp hybrid (10 wt. \% of HAp) was compared with the reference spectra of decellularized extracellular matrix (DEM) and Sigma Collagen I type (Fig. 14). Collagen comprised the group of Amides with characteristic signals in the range $3200-1200 \mathrm{~cm}^{-1}$ (Fig. 14a) [39]. Additionally, the mineral subregion started from $1200-500 \mathrm{~cm}^{-1}$ with the characteristic bands of HAp [40]. 
Phosphate group stretching (1045 and $\left.960 \mathrm{~cm}^{-1}\right)$ and bending $\left(597-588 \mathrm{~cm}^{-1}\right)$ vibrations indicated the HAp (Fig. 14b) [41]. Fig. 14a presented the peaks attributed to collagen at 2933, 1660, 1455 and $1250 \mathrm{~cm}^{-1}$ [39] [42]. 90Collagen10HAp had intensive peaks of phosphate groups and weak Amide bands related to the collagen (Fig.14a).

Raman spectra of UHMWPE as received and UHMWPE-Collagen hybrid were given in Fig. S3.1. The Raman spectrum of UHMWPE showed 'fingerprint' features at 1060, 1127, 1170, 1293, 1380, 1416, 1438, and $1455 \mathrm{~cm}^{-1}$ (Fig. S3.1) [43]. The intense peaks 1060 and $1127 \mathrm{~cm}^{-1}$ were caused by the $\mathrm{C}-\mathrm{C}$ stretching vibrations, and the peak at $1293 \mathrm{~cm}^{-1}$ was due to the $\mathrm{C}-\mathrm{H}$ twisting vibration [43].
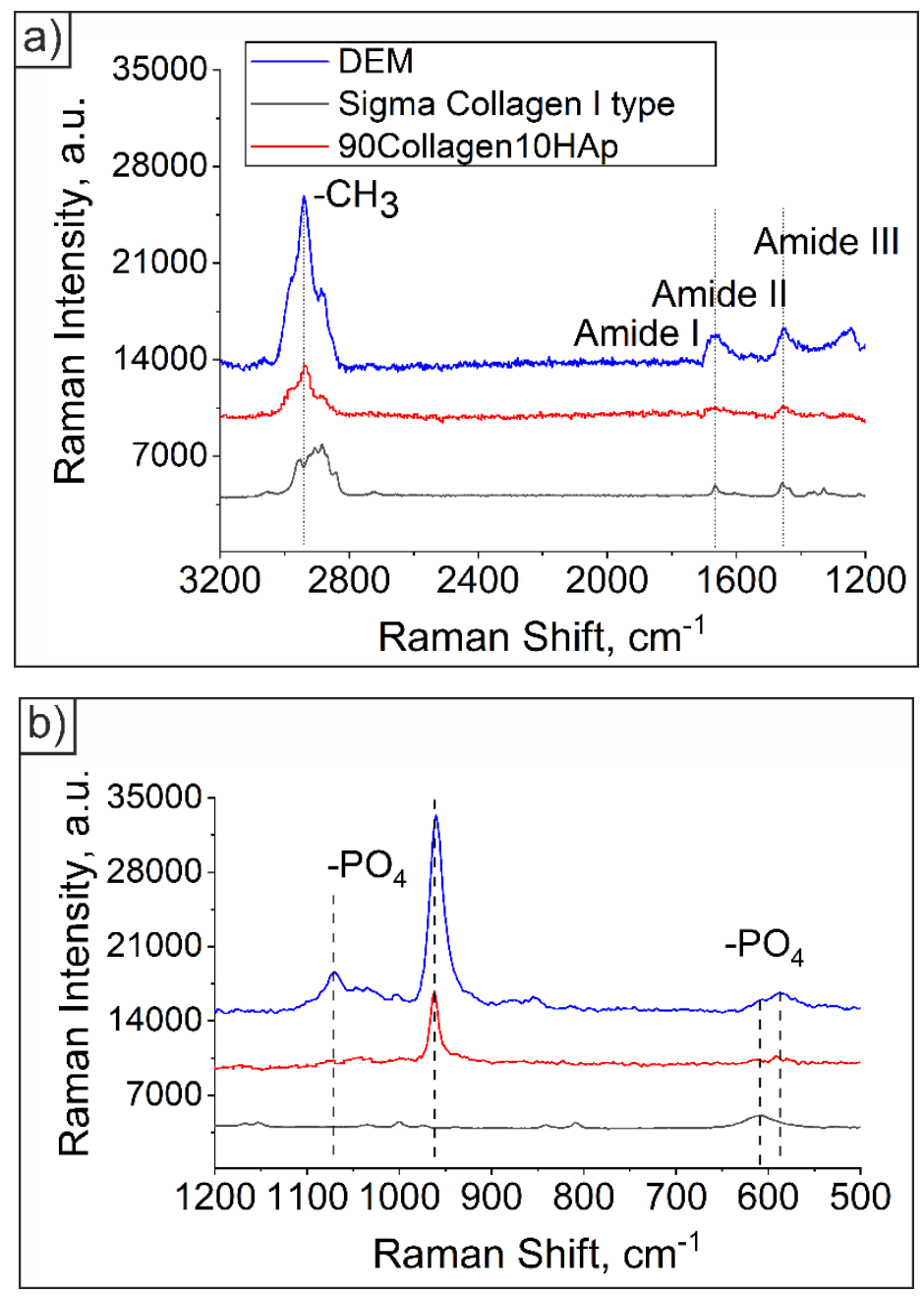

Fig. 14. Raman spectra for Collagen-HAp hybrid and reference samples: a) Amide subregion (3200-1200 $\left.\mathrm{cm}^{-1}\right)$; b) the subregion of Phosphate bonds $\left(1200-500 \mathrm{~cm}^{-1}\right)$.

There were also intense bands at 2847, 2881, and $2924 \mathrm{~cm}^{-1}$ corresponding to the $\mathrm{C}-\mathrm{H}$ stretching vibrations [44]. The Raman spectrum of the UHMWPE-Collagen hybrid was dominated by the above-mentioned very intense bands of UHMWPE, which masked the less intense Raman signals of 
collagen. Thus, Raman measurements could not confirm the presence of collagen within the sample as reliably as it was proved by FTIR spectroscopy (see Section 3.3).

\subsection{Micromechanical Bending Test}

The in-situ bending tests performed under an optical microscope allow direct observation of the macro-mechanisms, which facilitated a cracking and fracturing process. Fig. 15 showed the typical force-displacement curves of three-point bending tests plotted for the patch with the last layer of freeze-dried collagen (Fig. 15a) and 90Collagen10HAp (Fig. 15b), respectively. Moreover, the strain was calculated by the Digital Image Correlation (DIC) and compared to the theoretical prediction made using basic elastic beam bending theory [45], namely

$$
\frac{\sigma}{y}=\frac{E}{R} \text { or } \sigma=E \cdot \frac{y}{R}=E \cdot \epsilon,
$$

where $\sigma$ - stress [Pa], $y$ - displacement from the neutral line [pixel], $R$ - radius of curvature [pixel], E-Young's modulus [ Pa].

The estimated Young's modulus of UHMWPE-Collagen-HAp and UHMWPE-Collagen without HAp hybrids had close values that reached $1.23 \mathrm{GPa}$ and $1.27 \mathrm{GPa}$, respectively. Taking into the account that the bulk UHMWPE is the strain resistant component of the system with Young's modulus $0.7 \mathrm{GPa}$ [12], we conclude that the increased rigidity of UHMWPE-Collagen-HAp hybrid seems to reflect the synergetic contribution of non-UHMWPE layers.
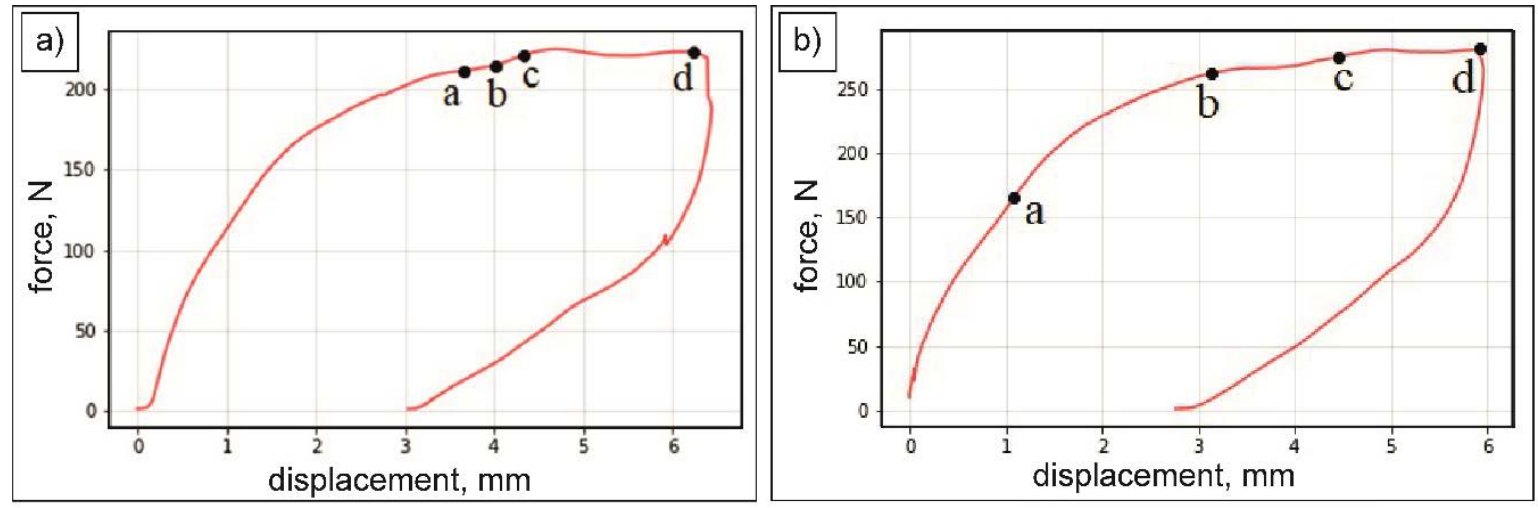

Fig. 15. The force-displacement curve of three-point bending test for a) Freeze-dried collagen hybrid; b) Collagen-HAp hybrid.

The sequence of images was taken during continuous loading of both hybrids (Fig. S4.1, Fig. S4.2). The more strain increased, the more progressive cracks opened, as shown in Fig. S4.1(c-d). At the initial stage, no damage was detected within the freeze-dried collagen layer at the displacement of 
$3.659 \mathrm{~mm}$ (Fig. S4.1a). A small crack appeared from the center of the layer at the displacement of $4.007 \mathrm{~mm}$ (Fig. S4.1b). Collagen-HAp layer showed a crack occurring at a smaller displacement $(1.106 \mathrm{~mm})$ in Fig. S4.2 compared to the freeze-dried collagen layer $(3.659 \mathrm{~mm})$, revealing brittle behavior of HAp.

The preliminary evaluation of the elasticity modulus indicated the negligible input of HAp and dominant one of bulk UHMWPE for both of the hybrids. Despite this, no visible delamination of the collagen-derived layer was in the interface zone for both specimens.

\subsection{Biocompatibility Tests}

Hemolysis of RBC occurs due to membrane damage during incubation and the subsequent release of hemoglobin in the extracellular medium. Biocompatible material should not induce hemolysis higher than $10 \%$. The percentage of hemolysis after incubation of RBC on the surface of the tested UHMWPE-Collagen hybrid was 0.6 (0.3-1.8) \% after 4 hours of co-incubation (see Fig.16a).

The vitality of WBC also did not significantly change after incubation with the studied samples in Fig.16b. A difference of OD (WBC+UHMWPE-Collagen hybrids) from control (intact WBC) was insignificant statistically $(\mathrm{p}=0.998)$ which indicated the absence of inhibition of cell viability after contact with the tested sample. Due to the proved biocompatibility of porous UHMWPE impregnated with collagen, the UHMWPE-Collagen-HAp hybrid including the bulk and porous UHMWPE layers was claimed as biocompatible.
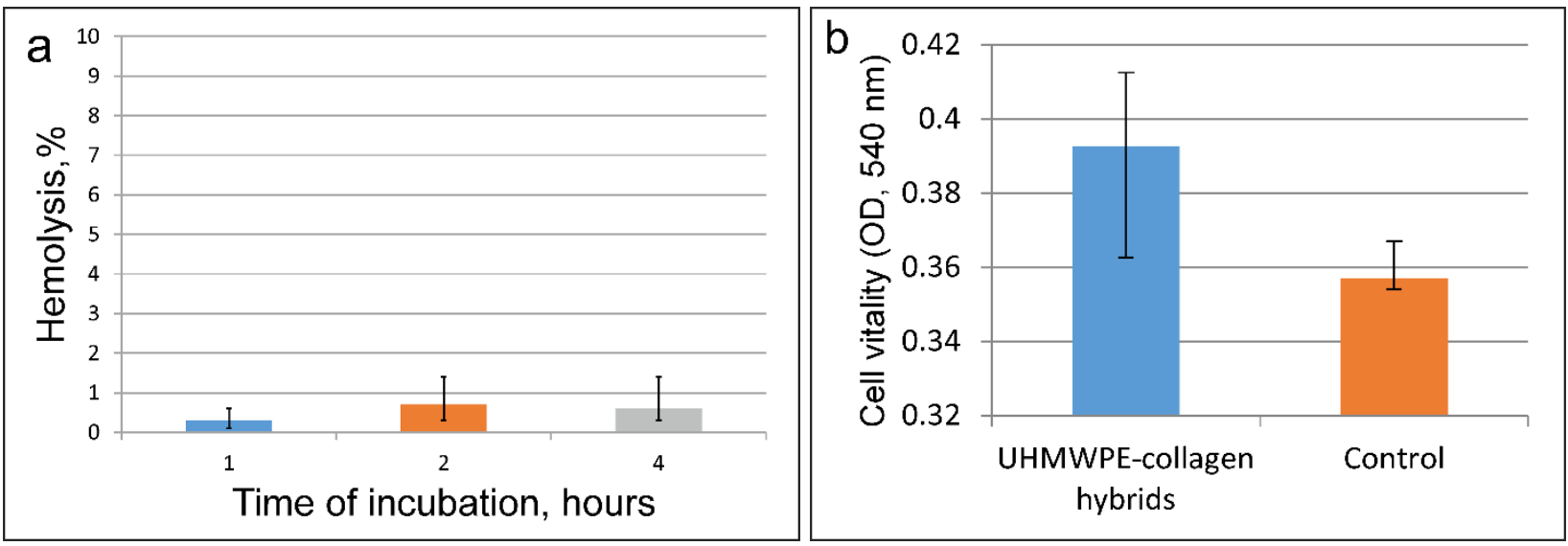

Fig. 16. Results of UHMWPE-Collagen hybrids biocompatibility tests: percentage of hemolysis after 1.2 and 4 hours of incubation (a); WBC vitality after incubation with the tested sample for 24 hours compared with the control (b). 


\section{Conclusions}

We introduced the gradual fabrication of UHMWPE-Collagen-HAp hybrid to treat the osteochondral defects. The concept of hierarchical structure allows creating of the new featured biomaterial layer by layer. The bioinert layer of UHMWPE with high wear and load resistance meets the requirement for the artificial cartilage. The sacrificial templating method and collagen impregnation provided the UHMWPE-Collagen hybrid with required pores for the cell affinity [24]. The method for creating a glue-free junction of bulk and porous layers [12] performs a gradient of porosity including changes of Young's modulus, and permeability to Collagen-HAp slurries. Freezecasting and drying promoted the open-porous structure of Collagen-HAp for osseointegration. The Collagen-HAp hybrid promoted the stable interface with the other layers proven by Deben tensile micro tests. Hence, each component made a valuable impact on the produced patch.

Alongside the creation of controlled gradient porosity of UHMWPE, several requirements to the cartilage-bone patch were reached: a) the modification of bulk UHMWPE to lower the friction coefficient; b) flexible variation of the collagen-to-HAp ratio; c) the wettability change of porous UHMWPE to hydrophilic for collagen affinity.

Due to the complex multi-stage nature of patch fabrication that may have affected the outcome, it was required to detect the collagen spectrum within the patch structure for quality assessment. ATR FTIR spectroscopy provided a strong criterion for the presence of collagen after the UHMWPECollagen preparation.

The outstanding challenges comprise the next tasks: to prove the mechanical properties and in vivo testing for further validation of the osseointegration. The biological tests would be carefully planned in terms of animal age for representative results.

\section{Acknowledgements}

This work was supported by the Federal Targeted Program "Research and Development in Priority Directions of Development of Scientific Technological Complex of Russia in 2014-2020", with the funding from The Ministry of Education and Science of Russian Federation: RFMEFI57817X0235 and the authors gratefully acknowledge the financial support of the Royal Society UK (IEC/R2/170223), EPSRC UK (EP/P005381/1) as the part of the development of architected UHMWPE trabecular-like structures. We are grateful for consultancy given by Istranova E.V. from Zelenaya Dubrava Company, Russia.

\section{Appendix A. Supplementary Materials}

Supporting Information (SI): Figures S1.1-S4.2. 


\section{References}

[1] F. Matassi, L. Nistri, D.C. Paez, M. Innocenti, New biomaterials for bone regeneration, Clin. Cases Miner. Bone Metab. 8 (2011) 21-24.

[2] Y. Wang, W. Cui, J. Chou, S. Wen, Y. Sun, H. Zhang, Electrospun nanosilicates-based organic/inorganic nanofibers for potential bone tissue engineering, Colloids Surfaces B Biointerfaces. 172 (2018) 90-97. https://doi.org/10.1016/j.colsurfb.2018.08.032.

[3] C.Y. Hu, T.R. Yoon, Recent updates for biomaterials used in total hip arthroplasty, Biomater. Res. 22 (2018). https://doi.org/10.1186/s40824-018-0144-8.

[4] J. Pajarinen, T.-H. Lin, T. Sato, Z. Yao, S.B. Goodman, Interaction of Materials and Biology in Total Joint Replacement - Successes, Challenges and Future Directions., J. Mater. Chem. B. 2 (2014) 7094-7108. https://doi.org/10.1039/C4TB01005A.

[5] M. Fang, N. Noiseux, E. Linson, P. Cram, The Effect of Advancing Age on Total Joint Replacement Outcomes, Geriatr. Orthop. Surg. Rehabil. 6 (2015) 173-179. https://doi.org/10.1177/2151458515583515.

[6] M.K. Musib, A Review of the History and Role of UHMWPE as A Component in Total Joint Replacements, Int. J. Biol. Eng. 1 (2012) 6-10. https://doi.org/10.5923/j.ijbe.20110101.02.

[7] T.D. Nguyen, J. Sukumaran, J. De Pauw, P. De Baets, Tribological behaviour of polymer bearings under dry and water lubrication, Int. J. Sustain. Constr. Des. 4 (2013). https://doi.org/10.21825/scad.v4i2.1048.

[8] T.M. McGloughlin, A.G. Kavanagh, Wear of ultra-high molecular weight polyethylene (UHMWPE) in total knee prostheses: A review of key influences, Proc. Inst. Mech. Eng. Part H J. Eng. Med. 214 (2000) 349-359. https://doi.org/10.1243/0954411001535390.

[9] A. V. Maksimkin, S.G. Nematulloev, D.I. Chukov, V.D. Danilov, F.S. Senatov, Bulk oriented UHMWPE/FMWCNT films for tribological applications, Polymers (Basel). 9 (2017). https://doi.org/10.3390/polym9110629.

[10] G. Huang, Z. Ni, G. Chen, Y. Zhao, The Influence of Irradiation and Accelerated Aging on the Mechanical and Tribological Properties of the Graphene Oxide/Ultra-High-MolecularWeight Polyethylene Nanocomposites, Int. J. Polym. Sci. 2016 (2016). https://doi.org/10.1155/2016/2618560.

[11] A. V. Maksimkin, S.D. Kaloshkin, V. V. Tcherdyntsev, D.I. Chukov, A.A. Stepashkin, Technologies for Manufacturing Ultrahigh Molecular Weight Polyethylene-Based Porous Structures for Bone Implants, Biomed. Eng. (NY). 47 (2013) 73-77. https://doi.org/10.1007/s10527-013-9338-5.

[12] A. V. Maksimkin, F.S. Senatov, N.Y. Anisimova, M. V. Kiselevskiy, D.Y. Zalepugin, I. V. Chernyshova, N.A. Tilkunova, S.D. Kaloshkin, Multilayer porous UHMWPE scaffolds for bone defects replacement, Mater. Sci. Eng. C. 73 (2017) 366-372.

https://doi.org/10.1016/j.msec.2016.12.104.

[13] A.M. Korsunsky, A 3DP-based procedure for the fabrication of artificial UHMWPE trabecular bone tissue, Biomater. Med. Appl. 02 (2018). https://doi.org/10.4172/2577-0268c1-001.

[14] D.Y. Zalepugin, A. V. Maksimkin, M. V. Kiselevsky, N.A. Tilkunova, N.Y. Anisimova, I. V. Chernyshova, T.S. Spirina, F.S. Senatov, M.I. Vlasov, Impregnation of Ultrahigh- 
Molecular-Weight Polyethylene with Amoxicillin in Subcritical Freon R22 Media, Russ. J. Phys. Chem. B. 11 (2017) 1215-1222. https://doi.org/10.1134/S1990793117080152.

[15] I.B. Anwar, A. Santoso, E. Saputra, R. Ismail, J. Jamari, E. Van Der Heide, Initial response of human bone marrow-derived stem cells after contact with ultrahigh-molecular-weight polyethylene (UHMWPE) material: An in vitro study on cell viability and interleukin-6 expression, J. Pharm. Bioallied Sci. 10 (2018) 43-47.

https://doi.org/10.4103/jpbs.JPBS_70_17.

[16] J. Bočková, L. Vojtová, R. Přikryl, J. Čechal, J. Jančář, Collagen-grafted ultra-high molecular weight polyethylene for biomedical applications, Chem. Pap. 62 (2008). https://doi.org/10.2478/s11696-008-0076-1.

[17] A.M. Haaparanta, E. Järvinen, I.F. Cengiz, V. Ellä, H.T. Kokkonen, I. Kiviranta, M. Kellomäki, Preparation and characterization of collagen/PLA, chitosan/PLA, and collagen/chitosan/PLA hybrid scaffolds for cartilage tissue engineering, J. Mater. Sci. Mater. Med. 25 (2014) 1129-1136. https://doi.org/10.1007/s10856-013-5129-5.

[18] C.M. Brougham, T.J. Levingstone, N. Shen, G.M. Cooney, S. Jockenhoevel, T.C. Flanagan, F.J. O'Brien, Freeze-Drying as a Novel Biofabrication Method for Achieving a Controlled Microarchitecture within Large, Complex Natural Biomaterial Scaffolds, Adv. Healthc. Mater. 6 (2017). https://doi.org/10.1002/adhm.201700598.

[19] G.S. Offeddu, J.C. Ashworth, R.E. Cameron, M.L. Oyen, Multi-scale mechanical response of freeze-dried collagen scaffolds for tissue engineering applications, J. Mech. Behav. Biomed. Mater. (2015). https://doi.org/10.1016/j.jmbbm.2014.10.015.

[20] C.J. Lowe, I.M. Reucroft, M.C. Grota, D.I. Shreiber, Production of Highly Aligned Collagen Scaffolds by Freeze-drying of Self-assembled, Fibrillar Collagen Gels, ACS Biomater. Sci. Eng. 2 (2016) 643-651. https://doi.org/10.1021/acsbiomaterials.6b00036.

[21] E.J. Sheehy, G.M. Cunniffe, F.J. O’Brien, Collagen-based biomaterials for tissue regeneration and repair, Pept. Proteins as Biomater. Tissue Regen. Repair. (2017) 127-150. https://doi.org/10.1016/B978-0-08-100803-4.00005-X.

[22] M.C. Varley, S. Neelakantan, T.W. Clyne, J. Dean, R.A. Brooks, A.E. Markaki, Cell structure, stiffness and permeability of freeze-dried collagen scaffolds in dry and hydrated states, Acta Biomater. 33 (2016) 166-175. https://doi.org/10.1016/j.actbio.2016.01.041.

[23] H. Li, W. Cheng, K. Liu, L. Chen, Y. Huang, X. Wang, Z. Lv, J. He, C. Li, Reinforced collagen with oxidized microcrystalline cellulose shows improved hemostatic effects, Carbohydr. Polym. 165 (2017) 30-38. https://doi.org/10.1016/j.carbpol.2017.02.023.

[24] J. Jeong, J.H. Kim, J.H. Shim, N.S. Hwang, C.Y. Heo, Bioactive calcium phosphate materials and applications in bone regeneration, Biomater. Res. 23 (2019) 1-11. https://doi.org/10.1186/s40824-018-0149-3.

[25] S. Bose, S. Vahabzadeh, A. Bandyopadhyay, Bone tissue engineering using 3D printing, Mater. Today. 16 (2013) 496-504. https://doi.org/10.1016/j.mattod.2013.11.017.

[26] W. Suchanek, M. Yoshimura, Processing and properties of hydroxyapatite-based biomaterials for use as hard tissue replacement implants, J. Mater. Res. 13 (1998) 94-117. https://doi.org/10.1557/JMR.1998.0015.

[27] J. Wang, C. Liu, Biomimetic collagen/hydroxyapatite composite scaffolds: Fabrication and characterizations, J. Bionic Eng. 11 (2014) 600-609. https://doi.org/10.1016/S1672- 
6529(14)60071-8.

[28] S.D. Ã, E. Saiz, A.P. Tomsia, Freeze casting of hydroxyapatite scaffolds for bone tissue engineering, 27 (2006) 5480-5489. https://doi.org/10.1016/j.biomaterials.2006.06.028.

[29] N.Y. Anisimova, M. V. Kiselevsky, I. V. Sukhorukova, N. V. Shvindina, D. V. Shtansky, Fabrication method, structure, mechanical, and biological properties of decellularized extracellular matrix for replacement of wide bone tissue defects, J. Mech. Behav. Biomed. Mater. 49 (2015) 255-268. https://doi.org/10.1016/j.jmbbm.2015.05.009.

[30] S. V. Dobatkin, E.A. Lukyanova, N.S. Martynenko, N.Y. Anisimova, M. V. Kiselevskiy, M. V. Gorshenkov, N.Y. Yurchenko, G.I. Raab, V.S. Yusupov, N. Birbilis, G.A. Salishchev, Y.Z. Estrin, Strength, corrosion resistance, and biocompatibility of ultrafine-grained $\mathrm{Mg}$ alloys after different modes of severe plastic deformation, in: IOP Conf. Ser. Mater. Sci. Eng., Institute of Physics Publishing, 2017. https://doi.org/10.1088/1757899X/194/1/012004.

[31] S. Henkelman, G. Rakhorst, J. Blanton, W. van Oeveren, Standardization of incubation conditions for hemolysis testing of biomaterials, Mater. Sci. Eng. C. 29 (2009) 1650-1654. https://doi.org/10.1016/j.msec.2009.01.002.

[32] P. M'Bemba-Meka, N. Lemieux, S.K. Chakrabarti, Role of oxidative stress, mitochondrial membrane potential, and calcium homeostasis in nickel sulfate-induced human lymphocyte death in vitro, Chem. Biol. Interact. 156 (2005) 69-80.

https://doi.org/10.1016/j.cbi.2005.07.004.

[33] C.M. Murphy, M.G. Haugh, F.J. O'Brien, The effect of mean pore size on cell attachment, proliferation and migration in collagen-glycosaminoglycan scaffolds for bone tissue engineering, Biomaterials. 31 (2010) 461-466.

https://doi.org/10.1016/j.biomaterials.2009.09.063.

[34] S. Cai, B.R. Singh, A Distinct Utility of the Amide III Infrared Band for Secondary Structure Estimation of Aqueous Protein Solutions Using Partial Least Squares Methods, Biochemistry. 43 (2004) 2541-2549. https://doi.org/10.1021/bi030149y.

[35] T. Riaz, R. Zeeshan, F. Zarif, K. Ilyas, N. Muhammad, S.Z. Safi, A. Rahim, S.A.A. Rizvi, I.U. Rehman, FTIR analysis of natural and synthetic collagen, Appl. Spectrosc. Rev. 53 (2018) 703-746. https://doi.org/10.1080/05704928.2018.1426595.

[36] L. Berzina-Cimdina, N. Borodajenko, Research of Calcium Phosphates Using Fourier Transform Infrared Spectroscopy, Infrared Spectrosc. - Mater. Sci. Eng. Technol. (2012). https://doi.org/10.5772/36942.

[37] W. Li, M. Feng, X. Liu, M. Huang, R. Ma, Ultra-High Molecular Weight Polyethylene Fibers/Epoxy Composites: Effect of Fiber Treatment on Properties, Fibers Polym. 20 (2019) 421-427. https://doi.org/10.1007/s12221-019-8704-7.

[38] W. Li, R. Li, C. Li, Z.R. Chen, L. Zhang, Mechanical properties of surface-modified ultrahigh molecular weight polyethylene fiber reinforced natural rubber composites, Polym. Compos. 38 (2017) 1215-1220. https://doi.org/10.1002/pc.23685.

[39] M.G. Martinez, A.J. Bullock, S. MacNeil, I.U. Rehman, Characterisation of structural changes in collagen with Raman spectroscopy, Appl. Spectrosc. Rev. 0 (2019) 1-34. https://doi.org/10.1080/05704928.2018.1506799.

[40] C.G. Kontoyannis, N.C. Bouropoulos, P.G. Koutsoukos, Raman spectroscopy: A tool for the 
quantitative analysis of mineral components of solid mixtures. The case of calcium oxalate monohydrate and hydroxyapatite, Vib. Spectrosc. 15 (1997) 53-60.

https://doi.org/10.1016/S0924-2031(97)00025-8.

[41] C. Popa, M. Albu, A. Costescu, C. Luculescu, R. Trusca, S. Antohe, Structural Characterization and Optical Properties of Hydroxyapatite/Collagen matrix, Rom. Reports Phys. 4 (2005) 137-150. http://www.rrp.infim.ro/2016_68_3/A22.pdf.

[42] A. Carden, R.M. Rajachar, M.D. Morris, D.H. Kohn, Ultrastructural changes accompanying the mechanical deformation of bone tissue: A Raman imaging study, Calcif. Tissue Int. 72 (2003) 166-175. https://doi.org/10.1007/s00223-002-1039-0.

[43] D.W. Hahn, D.L. Wolfarth, N.L. Parks, Analysis of polyethylene wear debris using microRaman spectroscopy. A report on the presence of beta-carotene, J. Biomed. Mater. Res. 35 (1997) 31-37. https://doi.org/10.1002/(SICI)1097-4636(199704)35:1<31::AIDJBM4>3.0.CO;2-N.

[44] S. Affatato, E. Modena, S. Carmignato, P. Taddei, The use of Raman spectroscopy in the analysis of UHMWPE uni-condylar bearing systems after run on a force and displacement control knee simulators, Wear. 297 (2013) 781-790. https://doi.org/10.1016/j.wear.2012.10.002.

[45] A.M. Korsunsky, A Teaching Essay on Residual Stresses and Eigenstrains, Elsevier Inc., 2017. 


\section{Appendix A. Supplementary Materials}
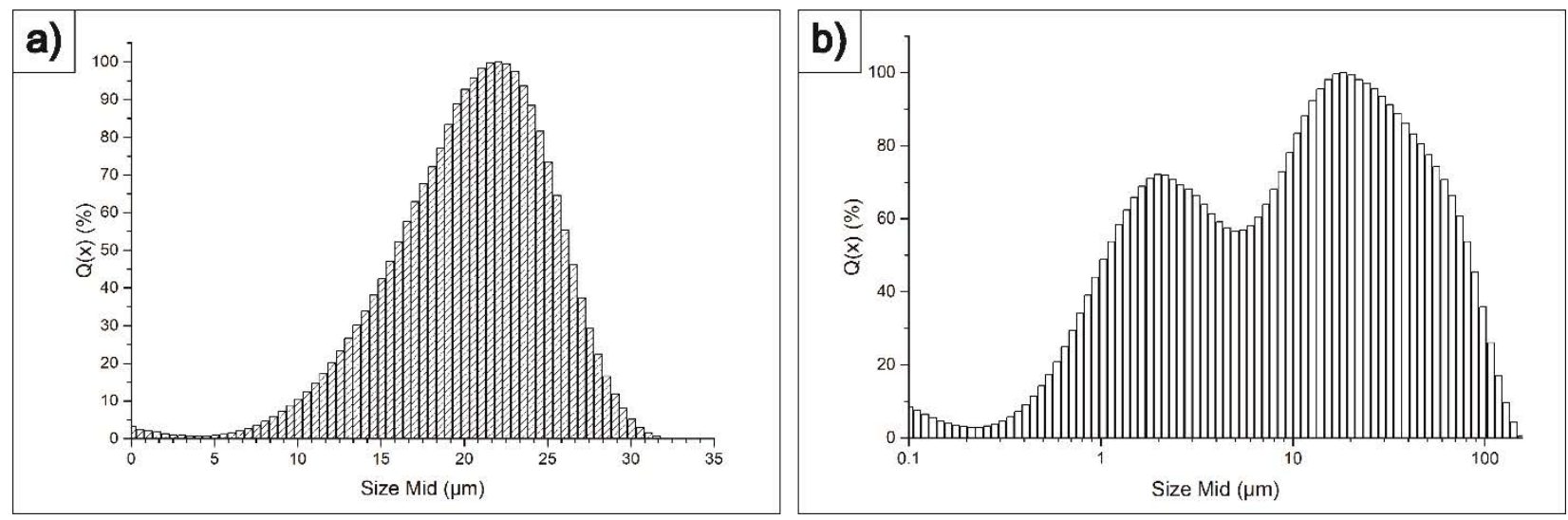

Fig.S1.1. Size distribution of: a) UHMWPE powder; b) Hydroxyapatite powder.

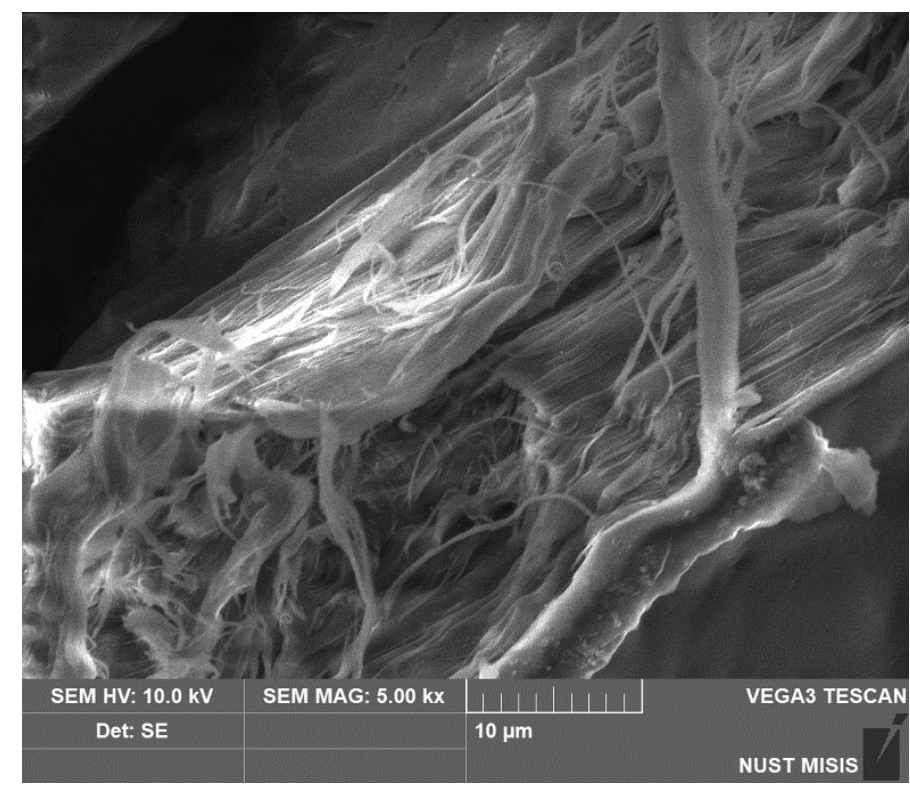

Fig. S1.2. SEM image of desiccated collagen film.
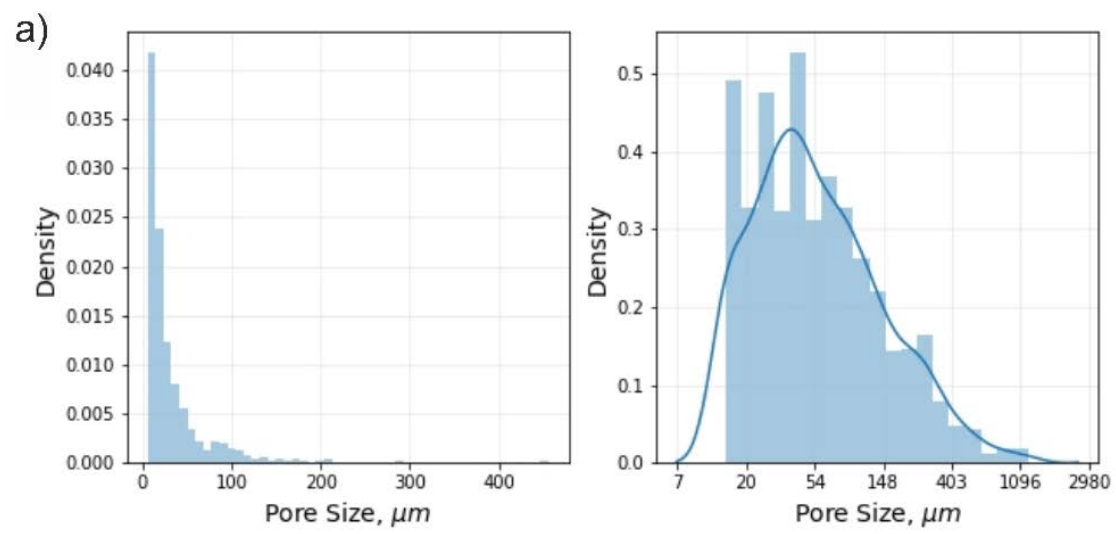

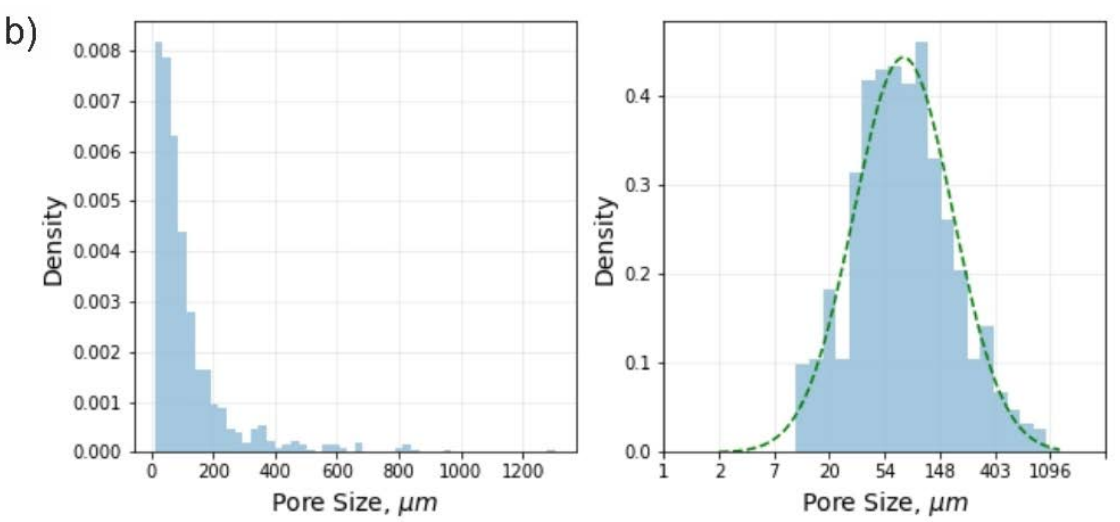

Fig. S1.3. The pore size distribution of: a) freeze-dried collagen; b) porous UHMWPE

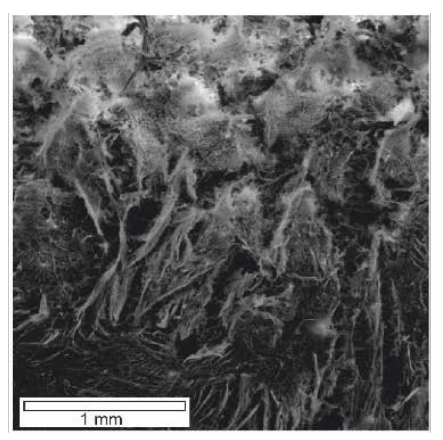

$\mathrm{S} \mathrm{K} \alpha 1$
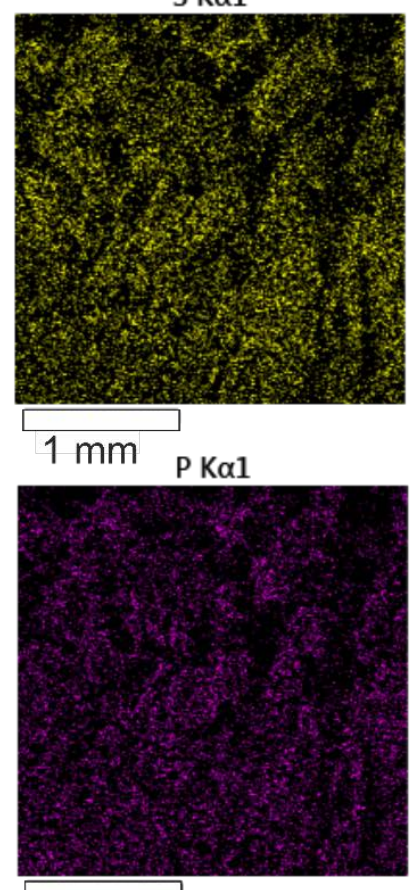

$1 \mathrm{~mm}$
C K $\alpha 12$
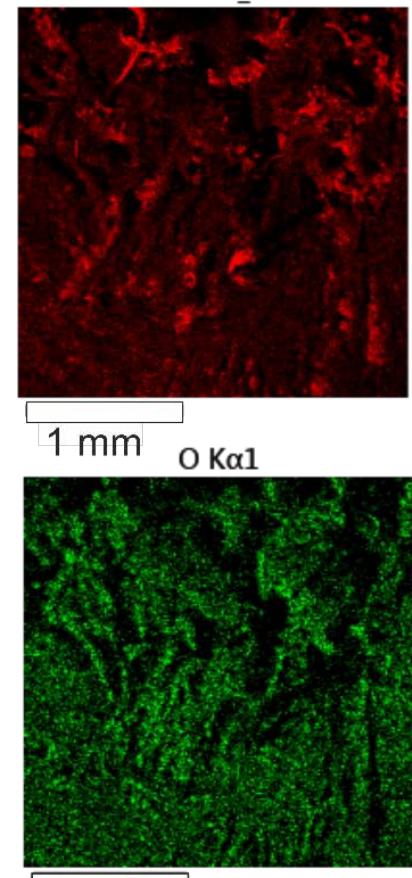

$1 \mathrm{~mm}$
Ca K $\alpha 1$

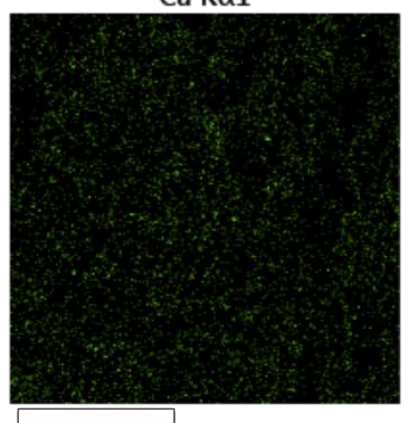

$1 \mathrm{~mm}$ Na Ka1_2

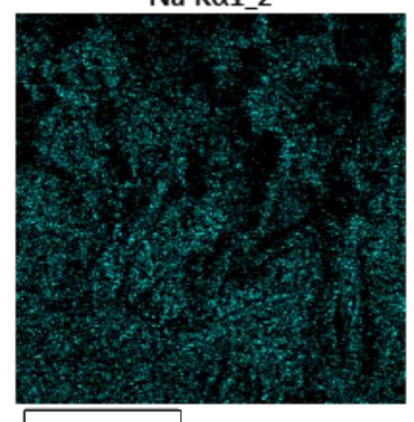

$1 \mathrm{~mm}$

Fig. S2.1. Elemental X-ray mapping of UHMWPE-Collagen layer. 

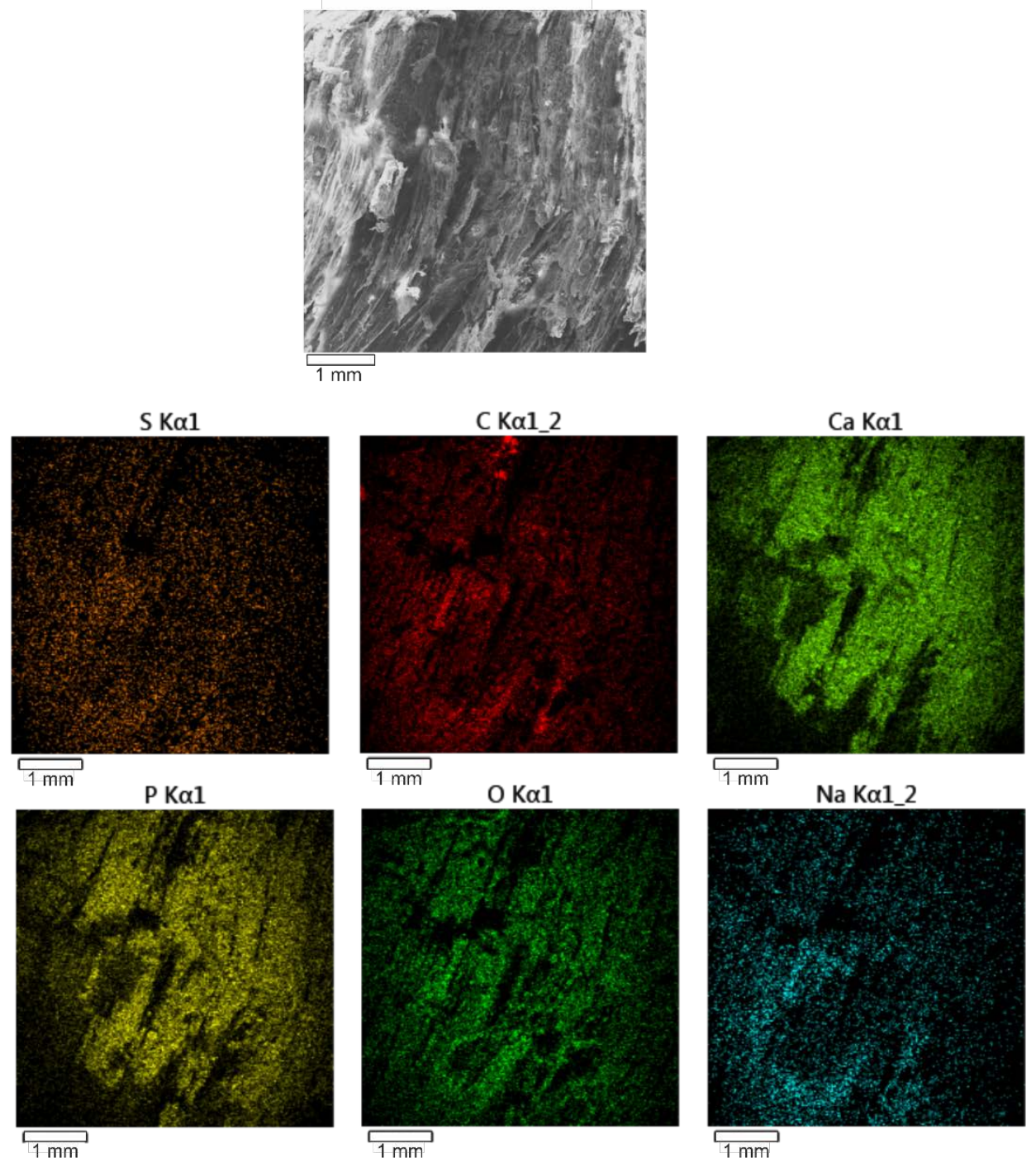

$1 \mathrm{~mm}$

Fig. S2.2. Elemental X-ray mapping of collagen-HAp layer. 


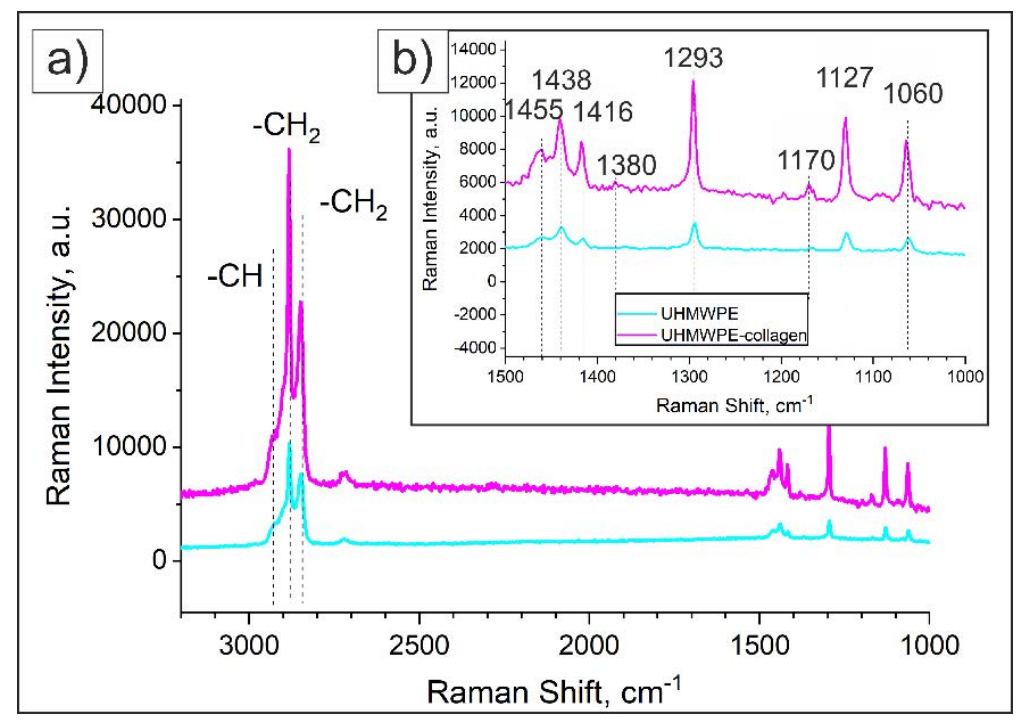

Fig. S3.1. Raman spectra for the UHMWPE-Collagen and UHMWPE: a) the whole spectrum of (3200-1000 $\left.\mathrm{cm}^{-1}\right)$; b) low Raman shift subregion (1500-1000 $\left.\mathrm{cm}^{-1}\right)$.
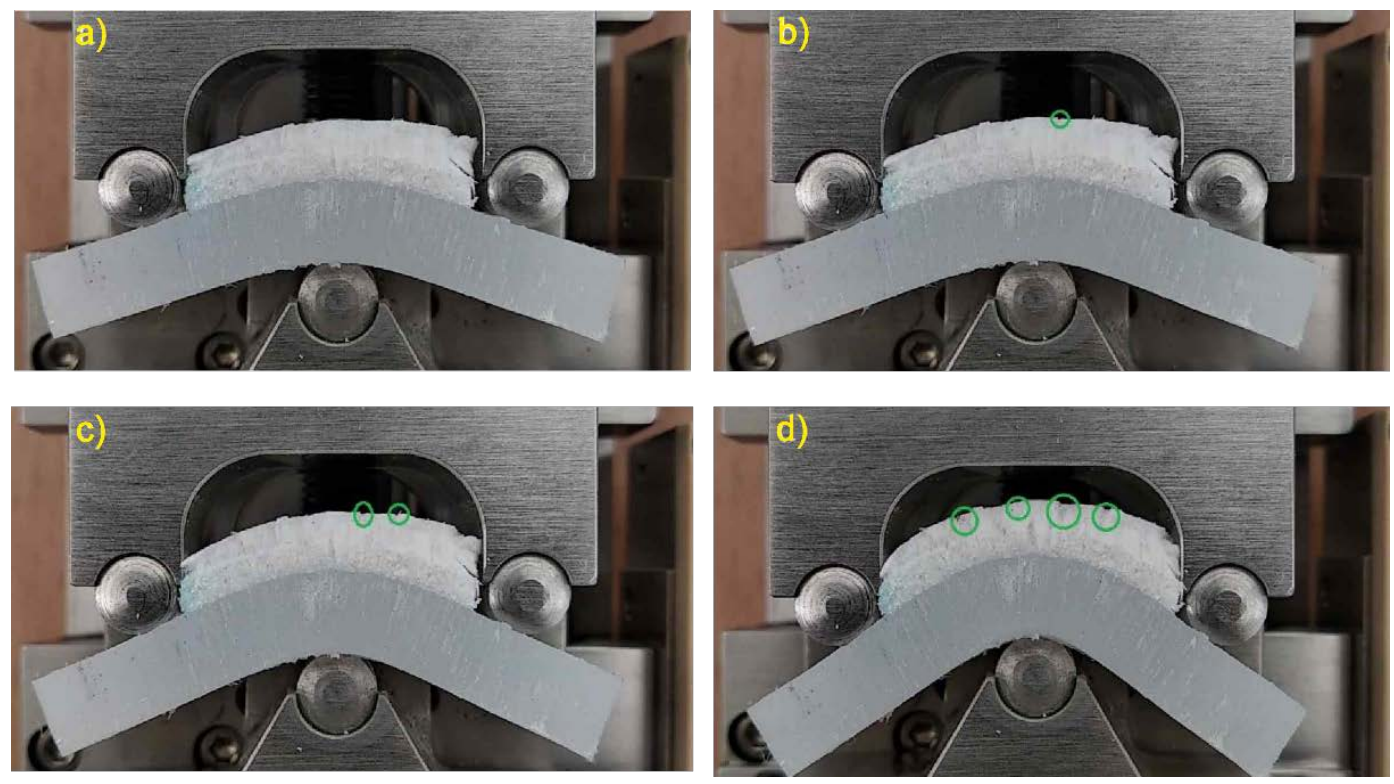

Fig. S4.1. The cracks development for the Freeze-dried collagen hybrid. 

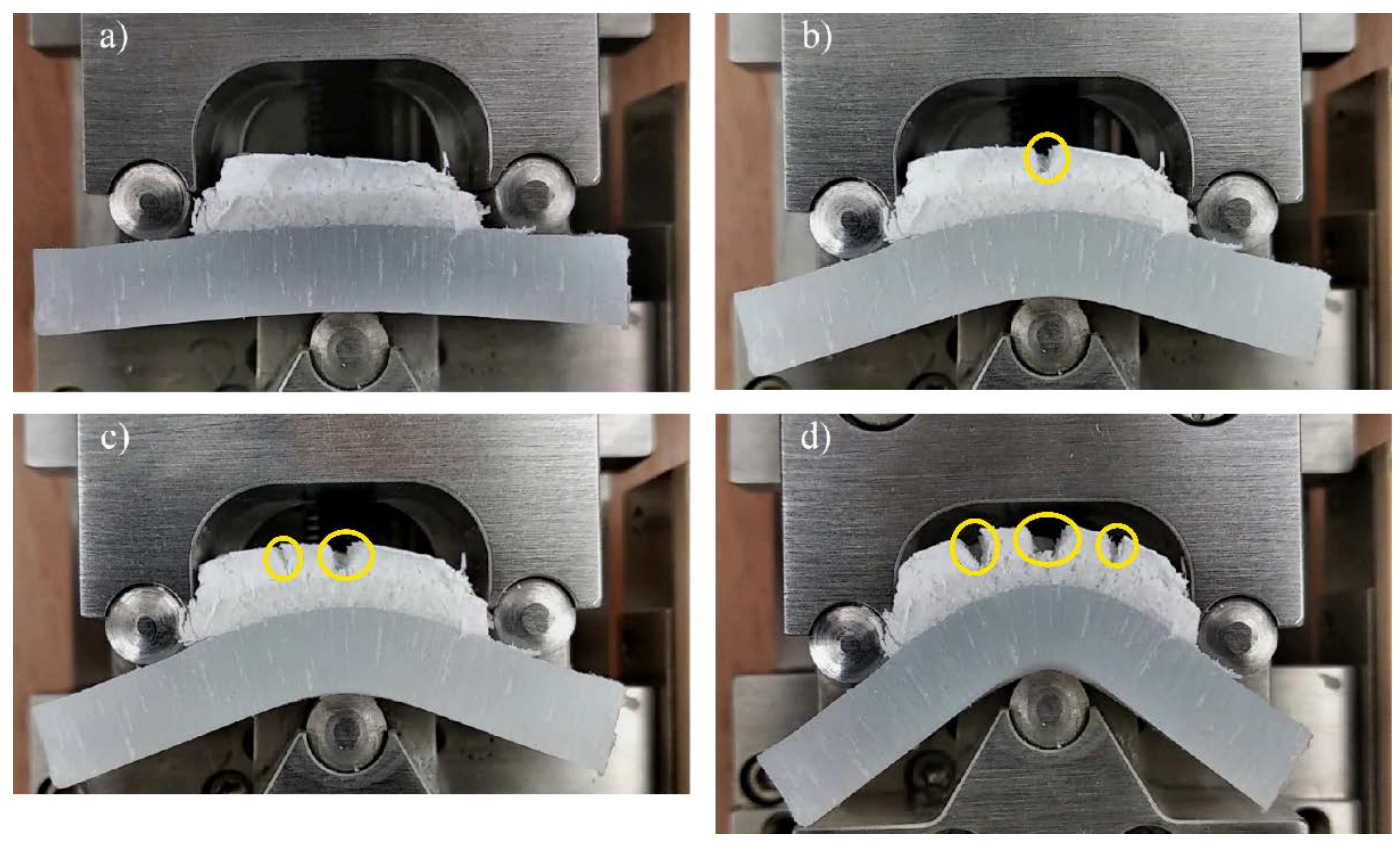

Fig. S4.2. The cracks development for the Collagen-HAp hybrid. 